\title{
A Review and Perspective on Particulate Matter Indices Linking Fuel Composition to Particulate Emissions from Gasoline Engines
}

\author{
Felix Leach, ${ }^{1}$ Elana Chapman, ${ }^{2}$ Jeff J. Jetter, ${ }^{3}$ Lauretta Rubino, ${ }^{4}$ Earl D. Christensen, ${ }^{5}$ Peter C. St. John, ${ }^{5}$ \\ Gina M. Fioroni, ${ }^{5}$ and Robert L. McCormick ${ }^{5}$
}

'University of Oxford, UK

${ }^{2}$ General Motors LLC, USA

${ }^{3}$ Honda R\&D Americas LLC, USA

${ }^{4}$ Opel Automobile GmbH, Germany

${ }^{5}$ National Renewable Energy Laboratory, USA

\section{Abstract}

Particulate matter (PM) indices-those linking PM emissions from gasoline engines to the composition and properties of the fuel-have been a topic of significant study over the last decade. It has long been known that fuel composition has a significant impact on particulate emissions from gasoline engines. Since gasoline direct injection (GDI) engines have become the market-leading technology, this has become more significant because the evaporative behavior of fuel increases in importance. Several PM indices have been developed to provide metrics describing this behavior and correlating PM emissions. In this article, 16 different PM indices are identified and collected-to the authors' knowledge, all of the indices are available at the time of writing. The indices are reviewed and discussed in the context of the information required to calculate them, as well as their utility. The authors believe that there is a need for indices that provide both a detailed and robust correlation, as well as those that are less sophisticated yet sufficient for specific use cases. Future research is suggested to guide the technical community toward improvements in the indices' methods and equations for both high and low fidelity and high and low time investment.

\section{History}

Received: 05 Feb 2021 Revised: 06 Jul 2021 Accepted: 28 Sep 2021 e-Available: 08 Oct 2021

\section{Keywords}

Gasoline, Spark-ignition, Particulate matter, Particle number, Emissions,

Particulate matter index, PMI, Honda index

\section{Citation}

Leach, F., Chapman, E., Jetter, J., Rubino, L. et al., "A Review and Perspective on Particulate Matter Indices Linking Fuel Composition to Particulate Emissions from Gasoline Engines," SAE Int. J. Fuels Lubr. 15(1):2022, doi:10.4271/04-15-01-0001.

ISSN: 1946-3952 e-ISSN: 1946-3960

c 2022 Felix Leach, General Motors, Jeff Jetter, Lauretta Rubino, Earl Christensen, Peter St. John, Gina Fioroni, Robert McCormick. Published by SAE International. This Open Access article is published under the terms of the Creative Commons Attribution License (http://creativecommons.org/licenses/by/4.0/), which permits distribution, and reproduction in any medium, provided that the original author(s) and the source are credited. 


\section{Introduction}

3 articulate matter (PM) emissions from vehicles have been regulated in some form since 1987. Many countries around the world will have new emissions regulations implemented over the next few years-spurred by concerns around air quality and public health in many of these territories. These new regulations involve significant reductions in gaseous emissions and particulates, which are measured by either mass or number, depending on the country and the certification level (see Figure 1). These new standards present significant challenges for original equipment manufacturers to meet, which have increased the awareness of all factors influencing engine-out emissions, including the composition and properties of gasoline-range fuel.

An increased understanding of the causes of PM emissions from gasoline engines has been developed in recent years. Automakers have made significant advancements to meet the regulations shown in Figure 1, but future emissions standards will be even more challenging. At the same time, regulation-driven technology changes are being implemented to improve fuel economy. According to "The $2020 \mathrm{EPA}$ Automotive Trends Report," $55 \%$ of original equipment manufacturers' model year 2020 cars were powered by a gasoline direct injection (GDI) engine and 35\% had turbocharging to meet their mandated fuel economy requirements [1]. These technologies have been shown to improve thermal efficiency and fuel economy, but direct injection can cause a significant increase in PM emissions [2, $\underline{3}]$. Figure 2 shows PM (particle or soot mass) and particle number (PN) emissions from vehicles with various engine technologies, including both a previous-generation port fuel injection (PFI) gasoline engine and a GDI engine. The PFI vehicle emitted roughly $1 \mathrm{mg} / \mathrm{km}$ of PM, whereas pre Euro 5 GDI vehicles had emissions as high as $15 \mathrm{mg} / \mathrm{km}$-although more typically around $5 \mathrm{mg} / \mathrm{km}$. The pre Euro 5 vehicles emitted PM in the same range as diesel vehicles not equipped with a diesel particulate filter. More modern Euro $5 / 6$ GDI cars were below $5 \mathrm{mg} / \mathrm{km}$, but in most cases, emissions at this technology level were higher than would be allowed by future regulations. Results are also shown for a GDI car equipped with a gasoline particulate filter (GPF) that are well below $1 \mathrm{mg} / \mathrm{km}$ and $6 \times 10^{11} \# / \mathrm{km}$. Results from a more recent study, shown in Figure 3 , also demonstrate that PM mass emissions (the central horizontal line in each box) are significantly higher for GDI vehicles as compared to the PFI vehicles at the same certification levels [4]. The authors conclude that the higher carbon emissions for the GDIs are due to spray impingement on the piston and wall, which is a fixed design feature of the combustion chambers. Although significant progress has been made in PM emissions reductions across the fleet of vehicles, additional improvements will be needed for carmakers to be able to utilize the downsized turbocharged GDI engines to simultaneously meet future fuel economy and emissions regulations.

One area of focus has been the effect of fuel composition. Gasoline is a variable mixture of hundreds of different hydrocarbon components, and these variations are substantial worldwide. Due to these compositional differences, different fuels will give rise to different levels of PM emissions. Therefore, understanding the influence of fuel composition on PM emissions is very important for comparing emissions results, as well as to work toward overall reductions in PM emissions. For example, the effect of changing a fuel specification to lower PM will reduce emissions from the entire on-road and off-road fleet. In 2010, the first index to correlate the composition of a fuel to the engine-out emissions was developed by Honda-the particulate matter index (PMI). The initial PMI work showed a very strong correlation $\left(R^{2}=0.95\right)$ between PMI and measured PM emissions. Today, the Honda PMI is considered the gold standard that other indices are compared to and is being used by various laboratories and original equipment manufacturers as a metric to understand

FIGURE 1 Implementation of particulate regulations (test cycles differ between countries).

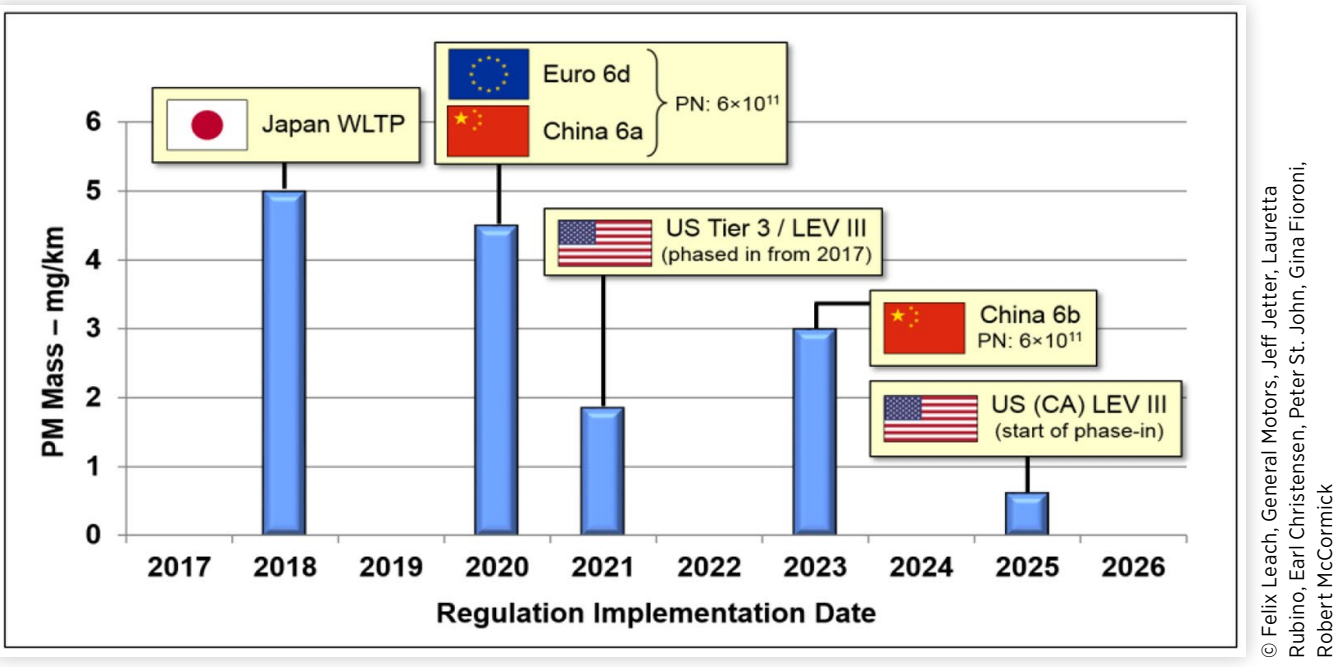




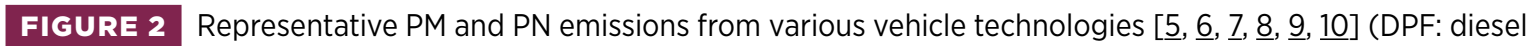
particulate filter).

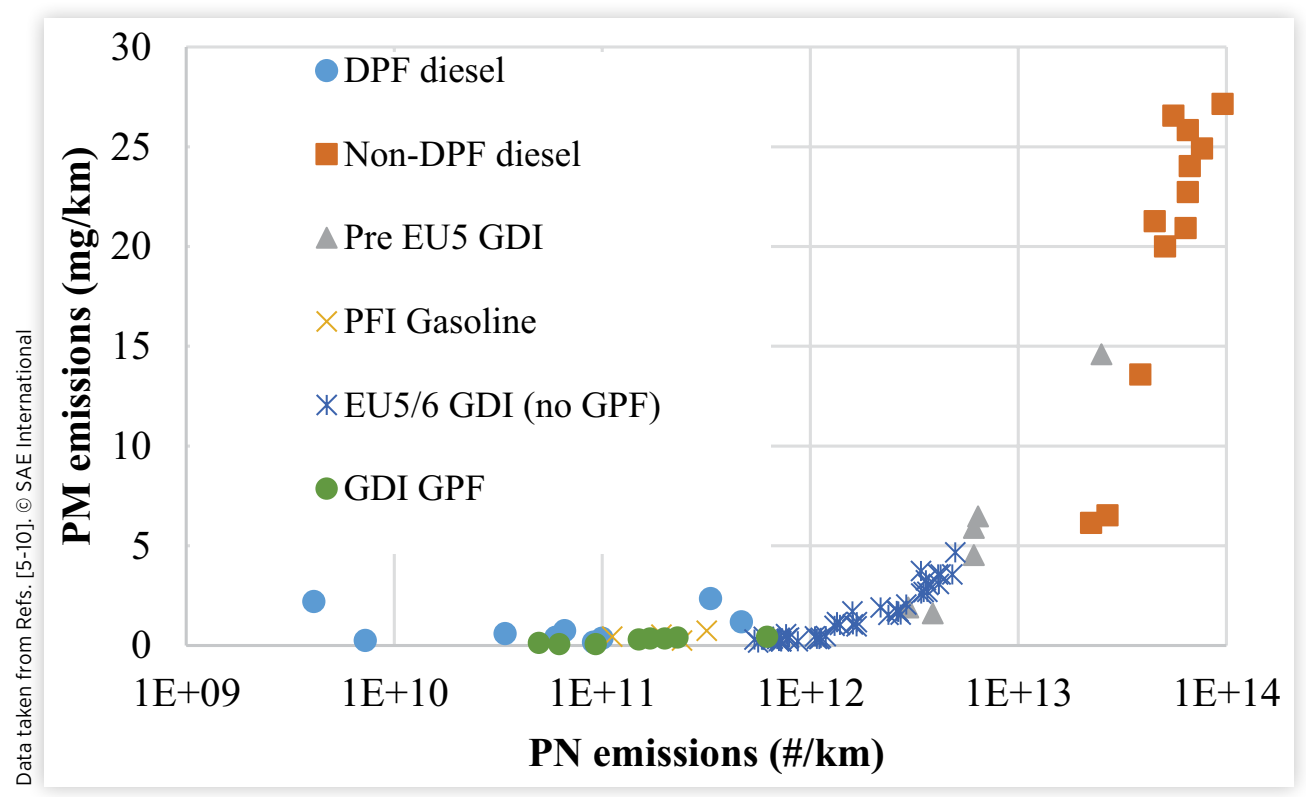

FIGURE 3 Results from a study of 82 cars from model years 1988-2014. Measured PM mass (shown in box-whiskers), median elemental carbon (EC, black diamond data points), and median primary organic aerosol (POA, green circle data points) emissions factors ( $\mathrm{mg} / \mathrm{mi}$ ) for different vehicle classes. Boxes represent the 25th to 75th percentiles, the horizontal line indicates the median, and the whiskers cover $99.3 \%$ of the data [4]. (LEV = low emission vehicle, ULEV = ultra-low emission vehicle, SULEV = super ultralow emission vehicle).

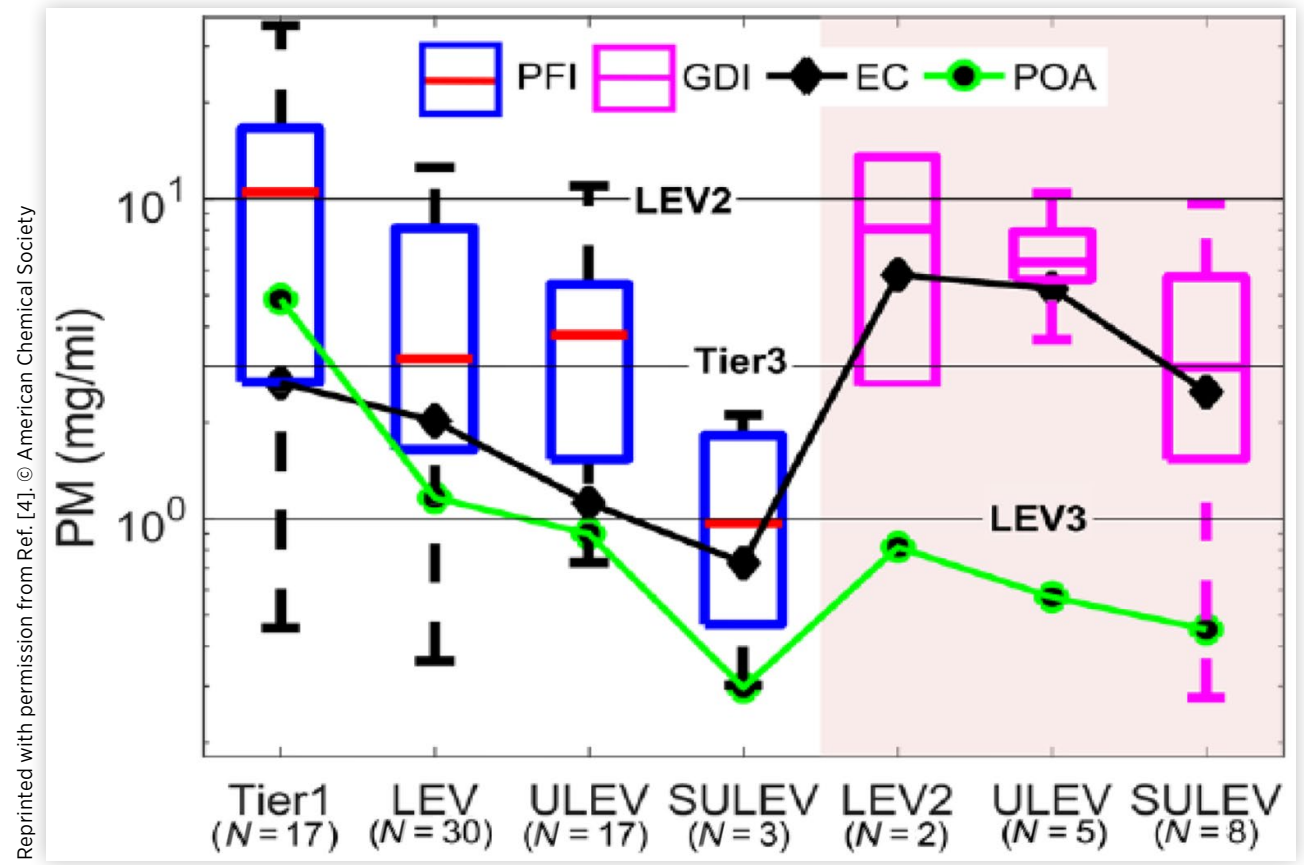


the impact of fuel composition on emissions. The index reveals the range of PM emission impacts of market fuels and how to create test fuels for use in the development of new technologies to meet future emissions standards. The stringency of these standards demands indices that predict emissions with high fidelity and that are based on analytical methods with high accuracy and precision across a range of fuels.

The PMI relies on a full detailed hydrocarbon analysis (DHA) - in other words, complete compositional analysis of the fuel in question. The gas chromatography (GC) configuration required for a DHA is common in research laboratories, it is much less so in labs found in a refinery or terminal. The method is also time consuming and requires a skilled operator/analyst. Thus an improved index based on a more widely accessible analytical methodology is desired. Hence, efforts are underway to provide correlations to the PMI using other chemical or physical analytical methods that are cheaper and quicker but still provide a strong correlation to a set of engine-out emissions data. The technical community has also suggested improvement in some of the methods, as well as the desire to coalesce around the ones that provide the best representation based on the accuracy needed for a particular task $[11, \underline{12}]$. Many of the PM indices discussed in this article provide a mechanism by which a fuel's PM-forming tendency relative to other fuels can be determined based on physical and/or chemical properties of the fuel rather than costly and time-consuming DHA. Accurate determination of those properties is critical. Such indices can facilitate the introduction of fuels with a lower PM-forming potential.

This article reviews the current state of the art in the development of these indices and proposes a path forward toward widespread implementation. We catalog all published methods known to the authors for predicting PM, PN, and chemical soot formation with indices, and explain the differences in each of these groups. We cover in more detail the needs for improved indices that provide greater accuracy and take longer to process, as well as those that are simple and quick. We also discuss the applicability of these indices in the future, such as on vehicles with GPFs, sub-23-nm particulates, and fuels containing ethanol at various levels. Finally, we discuss the need for a correlation that encompasses both the physical and chemical nature of a fuel, which may be more complex than the PMI number alone.

\section{PM/PN Measurements and Emissions Regulations}

\subsection{PM and PN Measurement}

Particle mass is usually measured (for legislative purposes) using a filter method. Here, after some specified dilution, temperature, and humidity control, the exhaust is passed through a filter, which captures the PM. The particle mass can then be determined by very precise weighing (accurate to 0.001-0.005 mg) of the collected sample. The filter captures multiple exhaust constituents that are collectively considered to be PM as defined by this method $[13,14,15]$. These constituents include, for example, elemental carbon (EC), organic carbon, and other material that has condensed onto the filter. Soot, also known as black carbon, can be readily measured directly from the exhaust with electronic instruments such as a micro soot sensor.

Where legislated, $\mathrm{PN}$ is measured in accordance with the Particle Measurement Programme (PMP) report [16] in virtually all jurisdictions (with a similar Real Driving Emissions [RDE] approach reported in [17]). Today, the PMP method captures particles down to a $\mathrm{D}_{50}(50 \%$ counting efficiency) of $23 \mathrm{~nm}$. However, there are engine technologies that can have high PN levels, especially below $23 \mathrm{~nm}$. This is supported by many different studies $[18,19, \underline{20}, \underline{21}, \underline{22}]$. For this reason, the forthcoming Euro 7 regulations will take into account $10 \mathrm{~nm}$ particles [23]. As a result, a number of recent projects have focused on this change $[\underline{24}, \underline{25}, \underline{26}]$. The PMP method counts only solid particles and specifies dilution and temperature requirements as well as the solid-particle-counting system needed (typically a condensation particle counter) to measure PN repeatably. The PMP method has been used widely for accurate PN measurements since its introduction as part of the Euro 5 legislation in 2011.

Numerous studies have reported correlations between $\mathrm{PM}$ and PN when measured in accordance with legislative requirements. Mass is obviously a conserved quantity, but number is not, so it is not immediately obvious that there should be a correlation between these two. Nevertheless, given the relatively constant size distributions emitted from gasoline engines, there is a strong correlation. We have summarized some correlations found in the literature in Table 1. Although there is some variability, a value of $2 \times 10^{12}$ particles $/ \mathrm{mg}$ is consistently seen. If we consider the data in Figure 2 , we can replot it to show these correlations for the different engine and emissions control technologies (Figure 4). The slope of the correlations seen in these data ranges from $4 \times 10^{11}$ particles/ $\mathrm{mg}$ (GDI GPF) to $2 \times 10^{12}$ particles/mg (Pre EU5 GDI) -in line with the figures seen in the literature (Table 1).

TABLE 1 PN-PM correlations from the literature.

\begin{tabular}{|c|c|}
\hline Correlation slope & Source \\
\hline $2.3 \times 10^{12}$ particles $/ \mathrm{mg}$ & [27] \\
\hline $2 \times 10^{12}$ particles $/ \mathrm{mg}$ & {$[\underline{28}]$} \\
\hline $2.7-3.8 \times 10^{12}$ particles $/ \mathrm{mg}$ & {$[\underline{29}]$} \\
\hline $0.2-2.0 \times 10^{12}$ particles $/ \mathrm{mg}$ & {$[\underline{30}]$} \\
\hline $\begin{array}{l}2 \times 10^{12} \text { particles } / \mathrm{mg} \text { (hot) and } 2.5 \times 10^{11} \\
\text { particles } / \mathrm{mg} \text { (cold) }\end{array}$ & [31] \\
\hline $2 \times 10^{12}$ particles $/ \mathrm{mg}$ & [32] \\
\hline $2.6 \times 10^{12}$ particles $/ \mathrm{mg}$ & [33] \\
\hline $3.8 \times 10^{12}$ particles $/ \mathrm{mg}$ & [34] \\
\hline
\end{tabular}


FIGURE 4 Replotted Figure 1 showing the PM-PN correlations.

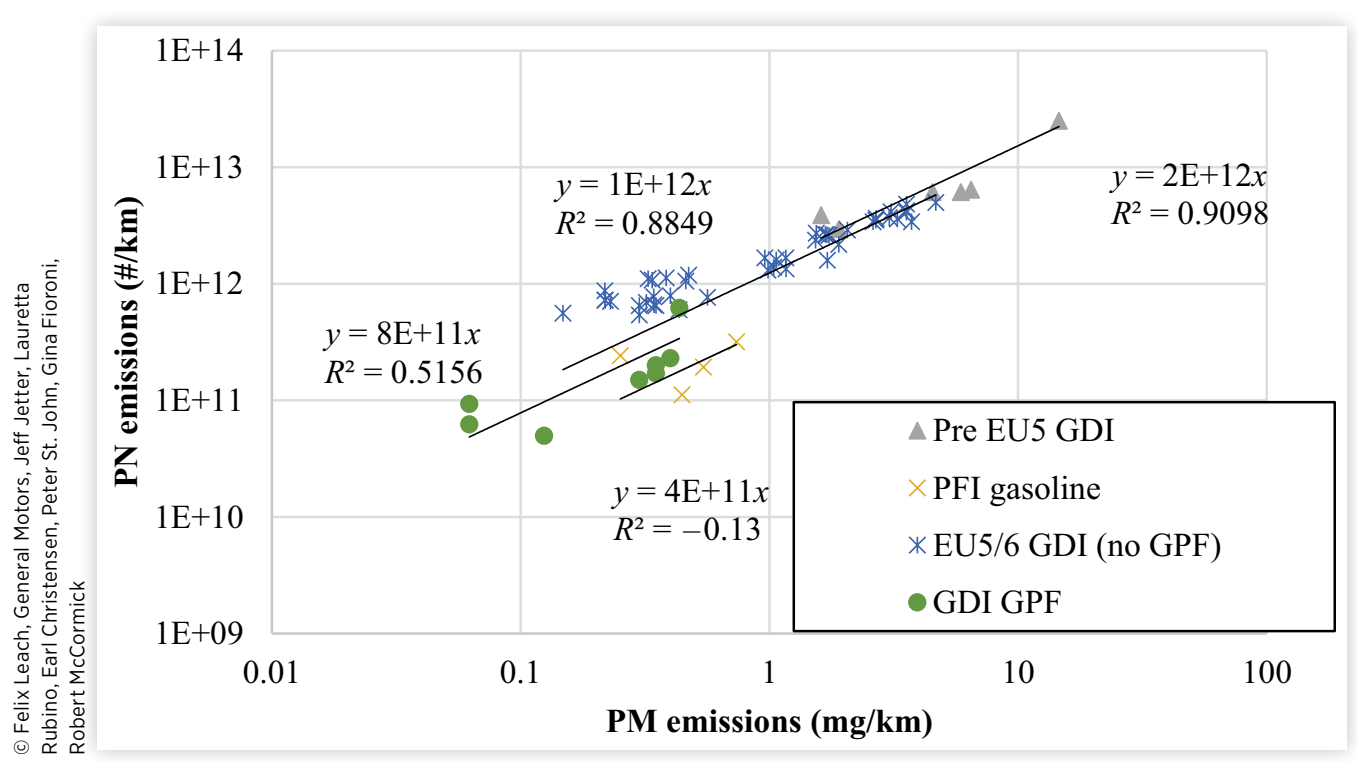

\section{2. $P M$ and $P N$ Emissions Regulations}

PM has been legislated as an emission since 1987 in California and since 1994 with the introduction of the Tier 1 standards in the United States. Globally, there are two main approaches to regulating pollutant emissions: those from the European Union and the United States. Most countries follow one of these two systems, with the main difference being the test cycles (World-Harmonized Light Vehicles Test Procedure [WLTP] vs. Federal Test Procedure 75 [FTP-75]) and whether $\mathrm{PN}$ is regulated. The global emissions standards for PM and PN (all normalized to per-kilometer emissions) are shown in the Appendix in Tables A.1 and A.2. Most standards worldwide are in reasonably close agreement. The standards have become far more stringent since they were first introduced. PM is now only permitted to be emitted at $1.5 \%$ of the first legislated standard. It can also be seen in Tables A.1 and A.2 that, in some jurisdictions, there are different standards for different vehicle technologies-gasoline, GDI, and, in the case of the Japanese legislation, stoichiometric GDI.

In order to narrow the gap between laboratory emissions and real-world emissions, the WLTP and the new RDE test procedures using Portable Emissions Measurement Systems (PEMS) have been recently introduced in Europe [35]. The main goal was to establish a more representative pollution test for cars and light commercial vehicles (vans). The European RDE regulation defines not-to-exceed limits for solid PN emissions, meaning that all valid RDE tests must result in emissions that satisfy those limits. These limits are defined via so-called conformity factors, which are multipliers of the reference emissions limit applicable to the laboratory procedure. The margin for PN was set to 0.5 in the third phase of RDE (conformity factor $=1.5$ ), which has been applied since September 1, 2018, for all new vehicles. The fourth phase of
$\mathrm{RDE}$ introduced the in-service conformity procedure and began on September 1, 2019, for which vehicles need to show compliance with their emissions limits throughout their defined normal life (5 years or $150,000 \mathrm{~km}$, whichever is sooner) under normal conditions of use. The conformity factors are greater than one to reflect the increased measurement uncertainty of PEMS instrumentation. These conformity factors are continuously reviewed based on decreased PEMS uncertainties. Further information may be found in $[\underline{36}, \underline{37}$, 38]. RDE is evaluated using whatever market fuel happens to be in the vehicle. In the absence of a PMI (or similar) limit for market fuel, it is possible that some market fuels that are outliers in terms of specification, but nevertheless compliant, could cause a PM compliance failure.

In addition to the tightening of $\mathrm{PN}$ emissions measurements regulating the $10-\mathrm{nm}$ particle size noted previously, the target of the future Euro 7 regulation is to guarantee the robustness of the standards by setting a "fuel-neutral approach" and make PN standards fuel neutral and technology neutral.

Very little information about a potential China 7 emissions regulation exists in published literature. However, some companies are noting that China $6 \mathrm{~b}$ is even more stringent than the Euro standards and, specifically, that China 7 will be a unique legislation [39]. One recent SAE paper by Ball et al. compares the Euro $6 \mathrm{~d}$ and China $6 \mathrm{~b}$ emissions limits for gasoline passenger cars [40]. The paper seems to suggest that the China $6 \mathrm{~b}$ limits may be the same as or close to the Euro 7 limits.

Given the impact that fuel composition has on PM formation, there are standards within the legislation to specify the composition of the fuel that can be used in a test (a reference or certification fuel) or allowed in the market (a market fuel). The parameters particularly relevant to PM formation from some common reference fuel standards are shown in Table 2. 
TABLE 2 Parameter ranges from legislative fuel specifications relevant to PM formation.

\begin{tabular}{|c|c|c|c|c|c|}
\hline & $\begin{array}{l}\text { EU5 reference } \\
\text { fuel }\end{array}$ & $\begin{array}{l}\text { EU6 reference } \\
\text { fuel }\end{array}$ & $\begin{array}{l}\text { EN228 market } \\
\text { fuel }\end{array}$ & $\begin{array}{l}\text { CARB LEV III } \\
\text { reference fuel }\end{array}$ & $\begin{array}{l}\text { EPA Tier } 3 \text { reference } \\
\text { fuel }\end{array}$ \\
\hline Vapor pressure (kPa) & $56.0-60.0$ & $56.0-60.0$ & $45.0-100.0$ & $47.6-49.6$ & $60.0-63.4$ \\
\hline E70a $(\%$ v/v) & $24-44$ & $34-46$ & $22-52$ & $n / a$ & $\mathrm{n} / \mathrm{a}$ \\
\hline $\mathrm{T} 10^{\underline{b}}\left({ }^{\circ} \mathrm{F}\right)$ & $\mathrm{n} / \mathrm{a}$ & $\mathrm{n} / \mathrm{a}$ & $\mathrm{n} / \mathrm{a}$ & $130-150$ & $120-140$ \\
\hline $\mathrm{E} 100 \subseteq(\% \mathrm{v} / \mathrm{v})$ & $48-60$ & $54-62$ & $46-72$ & $n / a$ & $n / a$ \\
\hline $\mathrm{T}^{0} \mathrm{O}^{\mathrm{d}}\left({ }^{\circ} \mathrm{F}\right)$ & $\mathrm{n} / \mathrm{a}$ & $\mathrm{n} / \mathrm{a}$ & $\mathrm{n} / \mathrm{a}$ & $205-215$ & $190-210$ \\
\hline T90 $\left({ }^{\circ} \mathrm{F}\right)$ & $\mathrm{n} / \mathrm{a}$ & $n / a$ & $\mathrm{n} / \mathrm{a}$ & $310-320$ & $315-335$ \\
\hline $\mathrm{FBP}^{\mathrm{g}}\left({ }^{\circ} \mathrm{C}\right)$ & $190-210$ & $170-195$ & 210 & 199 (max) & $193-216$ \\
\hline Olefins ( $\% \mathrm{v} / \mathrm{v})$ & $3.0-13.0$ & $6.0-13.0$ & $0-18.0$ & $4.0-6.0$ & $4.0-10.0(\% \mathrm{~m} / \mathrm{m})$ \\
\hline Oxygenates $(\% \mathrm{~m} / \mathrm{m})$ & 3.3-3.7 & $3.3-3.7$ & $0-3.7$ & $3.3-3.7$ & $n / a$ \\
\hline Ethanol (\%v/v) & $\mathrm{n} / \mathrm{a}$ & $n / a$ & $\mathrm{n} / \mathrm{a}$ & $9.8-10.2$ & $9.6-10.0$ \\
\hline C7 aromatics (\% v/v) & $\mathrm{n} / \mathrm{a}$ & $\mathrm{n} / \mathrm{a}$ & $\mathrm{n} / \mathrm{a}$ & $\mathrm{n} / \mathrm{a}$ & $5.2-6.4$ \\
\hline C8 aromatics (\% v/v) & $n / a$ & $\mathrm{n} / \mathrm{a}$ & $\mathrm{n} / \mathrm{a}$ & $n / a$ & $5.2-6.4$ \\
\hline C9 aromatics (\% v/v) & $\mathrm{n} / \mathrm{a}$ & $n / a$ & $\mathrm{n} / \mathrm{a}$ & $n / a$ & $5.2-6.4$ \\
\hline $\mathrm{C} 10+\operatorname{aromatics}(\% \mathrm{v} / \mathrm{v})$ & $\mathrm{n} / \mathrm{a}$ & $\mathrm{n} / \mathrm{a}$ & $\mathrm{n} / \mathrm{a}$ & $\mathrm{n} / \mathrm{a}$ & 4.4-5.6 \\
\hline
\end{tabular}

a Volume of fuel evaporated at $70^{\circ} \mathrm{C}$.

b Temperature at which $10 \%$ of the fuel has evaporated.

c Volume of fuel evaporated at $100^{\circ} \mathrm{C}$.

d Temperature at which $50 \%$ of the fuel has evaporated.

e Volume of fuel evaporated at $150^{\circ} \mathrm{C}$.

f Temperature at which $90 \%$ of the fuel has evaporated.

g Final boiling point.

Euro 5 and Euro 6 specifications are followed by most countries that have a PN standard, and other countries follow the United States (U.S.) approach. The more recent fuel standards (EU6 and LEV III) contain lower levels of aromatics and are, perhaps, slightly more representative of what is available in the market (and are E10, or 10\% ethanol by volume). Nevertheless, given the range of properties allowed for a given reference fuel a wide range of PM-forming tendencies is possible. One study reported a difference in the $\mathrm{PN}$ emissions of a factor of about 3 during tests of fuels within the EU5 reference fuel standard [41]. Some of the fuel specifications documented in Table 2 imperfectly attempt to account for PM formation. For example, the specifications for U.S. reference fuels include ranges for specific aromatic fractions to mitigate PM variability. A PMI limit for reference fuels and market fuels might be preferable.

As an aside, some markets require fuel detergent additives to prevent engine deposits. The fuels referenced in Table $\underline{2}$ do not specify any fuel additives, although they may be present for the market fuels. Note that in Europe, there is no regulation requirement for a maximum or minimum of any fuel additive. U.S. market fuels, although not used in certification testing, require a minimum detergent concentration $[\underline{42}, \underline{43}]$. It is clear that the use of deposit control additives can assist in minimizing $\mathrm{PM} / \mathrm{PN}$ emissions by controlling intake valve and fuel injector deposits, which hinder fuel-air mixing and thus increase the potential to form PM [ $\underline{44}, \underline{45}]$. Additionally, some additives may be carried in a heavy hydrocarbon suspension and not consumed in the combustion process, which could increase PM. A recently published study investigating the instantaneous impacts of fuel detergents on PM emissions within a clean engine revealed an optimal concentration of fuel detergent to minimize PM emissions separate from the deposit effects on the combustion process. Rather than the expected linear response as detergent concentration increased, lower PM emissions were witnessed at the mid-point TOP TIER ${ }^{\mathrm{TM}}$ dose in 2 of the 3 trails, which are approximately 2.5 times the U.S. federally required minimum detergency in fuel. Interestingly, at some very low doses, and all doses higher than current market levels, the PM increased from base fuel, indicting a role in the proper use of fuel detergents as a factor in minimizing PM emissions. Furthermore, after minimal carbon deposits accumulation within the engine, the PM was higher than any of the trails with fuel additives on the clean engine. Although outside the scope of this paper, it is important to note that both parts of the study indicate proper control of market fuel additives can aid in minimizing PM [44]]. 


\section{Chemical Tendency to Form Particles}

When burned, fuel molecules have different tendencies to form soot depending on their molecular structure. During combustion, compounds undergo unimolecular or bimolecular decomposition, resulting in fragments that further react to form either combustion products $\left(\mathrm{CO}_{2}\right.$ and $\left.\mathrm{H}_{2} \mathrm{O}\right)$ or small polycyclic aromatic hydrocarbon $(\mathrm{PAH})$ soot precursors. The soot formed during combustion of varying classes of hydrocarbon fuels largely depends on the propensity of their radical intermediates to form the first aromatic ring [46]. For instance, cleaner-burning small $\mathrm{n}$-alkanes decompose to primarily ethylene and methyl radicals, which overwhelmingly favor $\mathrm{CO}_{2}$ formation over the coupling and cyclization reactions that lead to soot formation. Longer-chain alkanes result in a greater number of propargyl and cyclopentadienyl radicals, which have low barriers toward the formation of the first aromatic ring [46]. Aromatic fuels sidestep many of these initial first barriers to PAH growth and tend to have the highest tendency to form soot. The role of oxygen moieties in PAH growth is complicated, and determining whether oxygen will impede or accelerate the formation of PAHs requires a detailed understanding of the mechanisms available to a given fuel at engine-relevant conditions [47].

A fuel's chemical structure continues to influence soot formation even after the first aromatic ring has formed. Growth of PAHs proceeds primarily through the hydrogen abstraction, acetylene addition mechanism (Figure 5) $[\underline{48}, \underline{49}$, 50]. This mechanism comprises a repetitive iteration of two reactions: firstly, the formation of an aromatic radical through the removal of a hydrogen atom and, secondly, the addition of an acetylene molecule to grow the PAH by two carbons. Successive rounds of these reactions can close newly formed aromatic rings and lead to the growth of large, multi-ring molecules. Oxidation of these PAH molecules is also possible, and the relative concentrations of reactant species leading to $\mathrm{PAH}$ growth versus oxidation alter the soot produced.

Because of the complex, multiscale nature of internal combustion engines, experimental measurement of a molecule's chemical sooting tendency is typically carried out under more controlled conditions. The most detailed experimental methods track gas species concentrations along with soot surface growth rates and nucleation rates to enable the construction of validated kinetic models of PM formation [51]. Although robust, these approaches are experimentally cumbersome, and building kinetic models to describe soot particle formation from first principles is typically limited to a number of small, well-studied molecules $[\underline{52}, \underline{53}]$. As a result, much of the knowledge on how oxygenates affect sooting tendency has been inferred from correlative methods that measure how readily different substances form soot in standardized laboratory flames.

The smoke point (or smoke height) is perhaps the earliest experimental method for determining the sooting propensity of organic compounds, first formalized in the 1930s. The smoke point measures the maximum height of a diffusion flame that can be achieved from a fuel source without producing any soot and was used to gain insight into the structural contributions of molecules in soot formation $[\underline{54}, \underline{55}, \underline{56}]$. However, raw smoke point measurements suffer from several limitations, most important of which were the apparatusdependent flame heights obtained. Calcote et al., therefore, introduced the threshold sooting index (TSI) in an effort to standardize and compare smoke point data from different laboratories [54]. The TSI was used to evaluate the effectiveness of oxygenates in reducing the sooting tendencies of gasoline blends [57]. For instance, the authors found that aldehydes and ketones were the most effective in reducing the TSI over similar alkanes, whereas for a constant volume fraction, esters and ethers were the least effective. In 2013, Barrientos et al. developed the oxygen-extended sooting index (OESI), another scaling of the smoke point measurement that explicitly accounts for the reduced stoichiometric need for air in oxygenate combustion [ [58]. This rescaled index corrected several errors in the estimated sooting tendencies for oxygenates specifically, but similarly corroborated the evidence that aldehydes are more effective than ketones, alcohols, and ethers in suppressing soot formation. However, the results showed explicitly that oxygen content alone is insufficient in predicting a molecule's sooting tendency and that subtle variations in molecular structure are critical in determining sooting tendency.

FIGURE 5 Hydrogen abstraction, acetylene addition mechanism for ring growth during PAH formation. Successive rounds of chain extension can lead to large, multi-ring soot precursors.

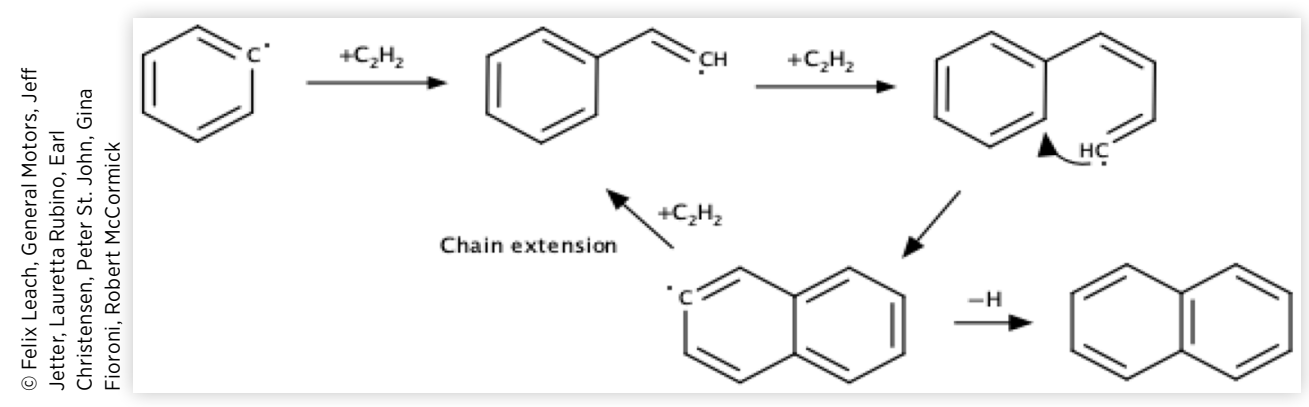


Despite its usefulness, the smoke point-based sooting indices suffer from several disadvantages, particularly when it comes to measuring the sooting tendency of oxygenates. Standardized smoke point methodology requires at least $20 \mathrm{~mL}$ of test compound, which limits the test to compounds that can be synthesized economically in quantities sufficient for testing [59]. Because flame height is inversely proportional to sooting propensity, it is difficult to accurately measure highsooting compounds or those that do not produce a luminous flame, such as ethanol. Even for ideal conditions, an observer must qualitatively decide when the flame is sooting based off on the shape of the flame, leading to variations in measured smoke point and derived metrics, where some compounds can vary by $>20$ TSI units between studies.

Perhaps the largest database of the sooting tendencies of oxygenates has come from the development of the yield sooting index (YSI), which uses laser-induced incandescence [60] — and more recently color ratio pyrometry [61] — to determine sooting tendencies using only $20 \mu \mathrm{L}$ of sample. The efficiency of this test method has allowed the measurement of the sooting tendency of approximately 450 unique compounds, many of which contain oxygenated functional groups in varied configurations [62]. These results were the first to indicate that some oxygenate functionality may actually increase sooting tendency [63]. For instance, secondary alcohols were shown to have a higher YSI than n-alkanes of the same length, whereas esters were found to have either an increased or decreased YSI over n-alkanes with the same carbon content depending on whether the molecular structure could react via the four- or six-center reactions. For unsaturated esters, the position of the $\mathrm{C}=\mathrm{C}$ double bond relative to the carbonyl functional group qualitatively changes the molecule's sooting behavior [64]. When the $\mathrm{C}=\mathrm{C}$ double bond is directly connected to the carbonyl group, the YSI is comparable to that of the corresponding unsaturated ester; however, large increases in YSI are seen when the $\mathrm{C}=\mathrm{C}$ double bond is located farther away from the carbonyl linkage [64].

In evaluating potential fuels, and for developing emissions indices, estimates of a molecule's sooting tendency are often required. The simple approach developed and used in PMI is the double bond equivalent (DBE), based only on the molecular formula of each component [65]. A comparison of measured values for YSI, OESI, TSI, smoke point (via the normalized smoke point database) [66], and calculated DBE values is shown in Figure 6. Although sufficient for a rough estimation of sooting tendency, a concerted effort to develop methods to predict sooting tendency directly from molecular structure has resulted in published group contribution

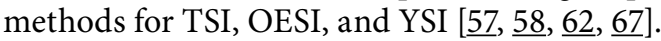

\section{Emissions Indices}

An emissions index is a calculated parameter that ranks fuels in terms of particle emissions from an engine or vehicle. Particle formation can be affected by factors such as fuel evaporation and mixing, and hence by fuel properties beyond just the chemical soot-formation tendency. Because soot, PM, and PN appear to be well correlated in most situations (as previously described), indices developed for all these forms of PM are considered together [33, 34, 65, 68]. Emissions indices can be generally grouped into two classes: those based on DHA and those based on bulk properties and less-detailed analysis. Because DHA is time consuming and requires a high level of chromatography expertise, it is generally considered to be a research method suitable for activities such as new fuel formulations and blending equation development. Methods based on bulk properties may be more practical for routine activities such as refinery process control or regulating fuels to have lower PM emissions.

\subsection{Indices Based on Detailed Chemical Analysis of the Fuel}

DHA of gasoline is commonly performed using GC with flame ionization detection (FID) using standardized methods [69, 70]. Less commonly, mass spectrometry (MS) is also used to identify high-boiling components, and in the most recent work, GC with vacuum ultraviolet (VUV) detection has also been used [71]. It is typically the highest-molecular-weight components in gasoline, especially high-molecular-weight aromatic compounds, that are responsible for PM emissions $[\underline{72}, \underline{73}]$. As molecular weight increases, the number of possible chemical structures or isomers increases exponentially; therefore, the most recent work on improving DHA methods has focused on high-boiling, high-molecular-weight component identification and quantification.

\subsubsection{Methods for Detailed Analysis}

4.1.1.1. Conventional DHA. DHA methods utilize highresolution GC to speciate and quantify nearly every individual component in gasoline. Modern techniques typically use subambient (cryo-cooled) ovens to begin compound elution at low temperatures for isolation of C3 hydrocarbons and enhanced resolution of later eluting compounds $[\underline{70}, \underline{74}]$. A need for very slow temperature ramping to maximize resolution results in a relatively long analysis time, typically 120 minutes or longer. This procedure was developed utilizing known standards of hydrocarbon mixtures as well as GC-MS for the identification of individual peaks [75]. Although it may not be possible to conclusively identify each isomer without genuine standards from mass spectra alone, particularly at carbon numbers $>9$, the carbon number can be established by elution order and hydrocarbon class from characteristic mass spectral features. Standardized methods that do not utilize MS rely on retention indices compared to $n$-paraffins to establish the location of peaks on the chromatogram. From published tables of retention indices, individual components can be identified by retention time alone when following the specified analytical procedure $[\underline{69}, \underline{74}, \underline{76}, \underline{77}]$. Quantification 
FIGURE 6 Pair plot of different sooting index metrics. Experimental values compared include the normalized smoke point (plotted as the inverse) from [66], OESI and TSI from [58], and the unified YSI from [62]. The (DBE + 1) $M_{w}$ descriptor represents the mole-percent influence a given compound would contribute to the chemical structure portion of a fuel's PMI score. Blue points indicate non-oxygen-containing hydrocarbons, whereas red points indicate those containing oxygen. Pearson correlation coefficients between each pair of sooting metrics are shown for only oxygenates in red and for non-oxygen-containing hydrocarbons in blue.

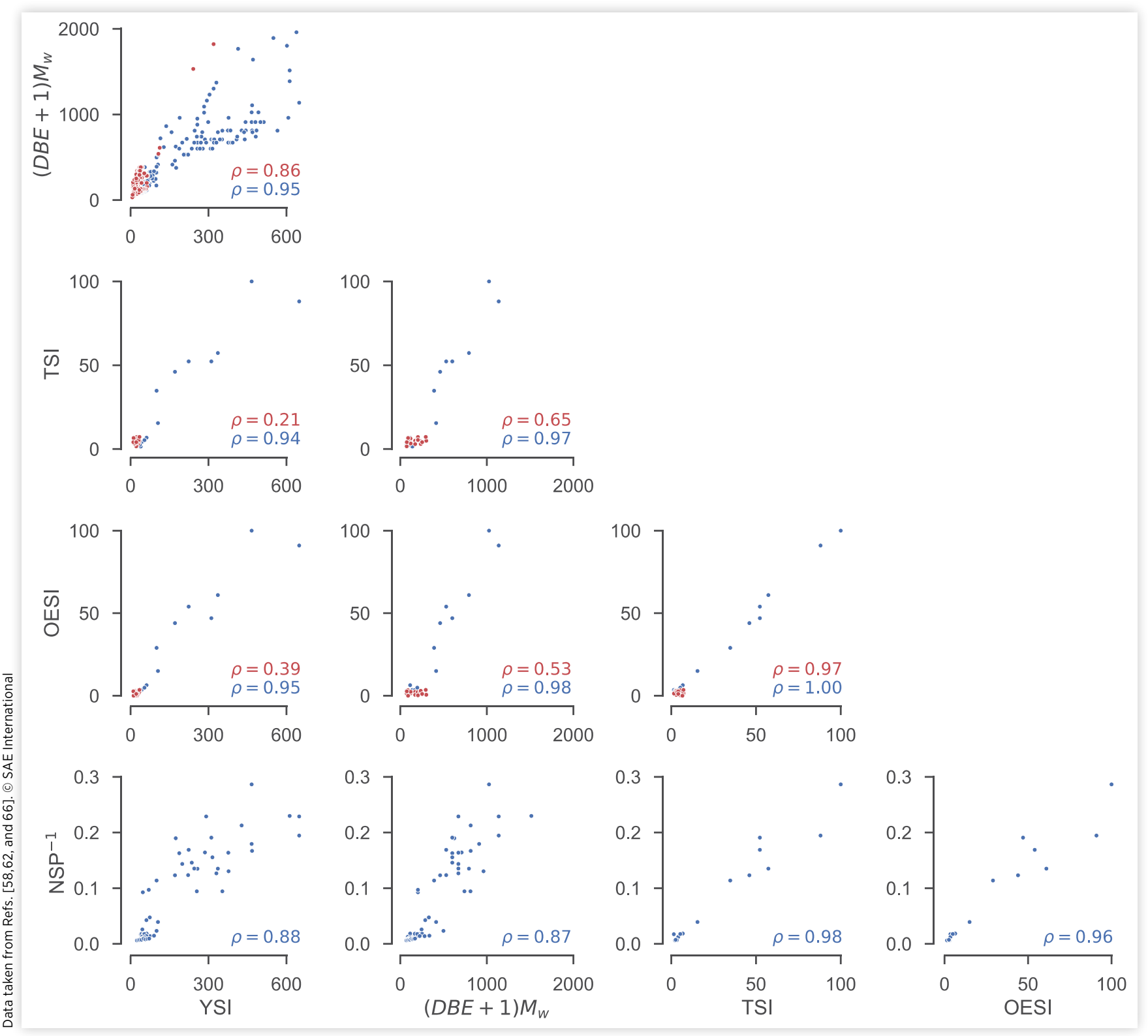


of compounds is realized by using FID. These detectors have a very large linear dynamic range and sensitivity, making them ideal for measuring the wide range of concentrations of compounds in gasoline, ranging from hundredths of a percent to $30 \%$ or more of the total sample mass. The response of an FID is also predicable and can be accurately approximated from compound formulae, which greatly reduces the effort required for mass-response calibration of hydrocarbon classes [78]. Oxygenates such as ethanol and methyl tert-butyl ether can similarly be quantified using an FID signal but may require more effort to establish response calibration and measurement accuracy.

Compositional analysis of gasoline can be simplified into compound class analyses. Data generated by DHA is typically binned into hydrocarbon classes-n-paraffins, iso-paraffins, olefins, naphthenes, and aromatics-and the simplified data sets are often described as PIONA measurements (paraffins, isoparaffins, olefins, naphthenes, and aromatics). This sort of generalized analysis of gasoline provides an overall compositional evaluation, which is useful in characterizing fuels and refinery streams.

Although the FID is very well suited for detection and quantitation of compounds in gasoline, this is a nonspecific detector and, therefore, does not provide qualitative information beyond retention time. Any variation in elution order caused by column stationary phase formulation will result in incorrect identification without the benefit of confirmation. In addition, co-elutions cannot be readily determined or deconvoluted. Near-complete resolution of all peaks is necessary to generate accurate data. Very careful evaluation of data is also needed to ensure correct assignments of peaks. Lab-to-lab precision is reliant not only on consistent execution of a procedure but also on analysts and/or software to correctly assign identifications. This can lend itself to not only long instrumental analysis times but relatively large amounts of time spent evaluating data. The inclusion of simultaneous MS analysis via post-column flow splitter allows for verification of compound IDs as well as isolation and deconvolution of co-elutions, but this instrumentation greatly increases cost and complexity.

DHA methods are very effective at speciating gasolinerange hydrocarbons of nine or fewer carbon atoms, as there are relatively few possible isomers resulting in less-complex chromatograms. In the region of the chromatogram associated with $\mathrm{C} 10$ to $\mathrm{C} 12+$ hydrocarbons, the chromatogram can become much more complex, with co-elutions becoming more commonplace and ambiguity of compound assignments by retention time leading to a decline in precision and accuracy. Identifying later eluting compounds via DHA is greatly assisted by the inclusion of MS. Despite these limitations in DHA, these techniques can be used to accurately measure more than $95 \%$ of the composition of a given gasoline, which allows for the prediction of key physical properties such as octane ratings [79], distillation temperatures $[\underline{80}]$, or heat of vaporization [1] , among others. These methods for measuring gasoline composition naturally lend themselves to developing a PMI.
4.1.1.2. Enhanced DHA. Species eluting late in the chromatogram are typically multi-substituted aromatics (C9+), and thus have a strong leveraging effect on the PMI given their high DBE and low vapor pressures; unidentified or misidentified peaks in this region can result in an inaccurate PMI determination. The American Society for Testing and Materials (ASTM) methods D6729 and D6730 [우, 무] can sometimes leave $5 \%$ or more of the total peak area unidentified, although the magnitude of this value is dependent upon fuel composition and laboratory technique. Lubkowitz and Meneghini developed an "enhanced" DHA based upon the D6730 method [11]. Additional gasoline component identifications were achieved by splitting the column effluent such that an FID and MS detector produced identical retention times. Specific identification of substituted naphthalene isomers was accomplished by using pure compounds. The final method contains 860 components, more than double that listed in D6730. The unidentified fraction was reduced to $<0.5 \%$. The enhanced method does not require an MS detector for routine operation, but a multicomponent standard and careful review of the chromatogram are necessary to maintain quality control. This method is documented in Appendix X1 of D6730, including individual PMI values for each component [70].

A comparison of PMI values calculated using the enhanced method and a traditional method (D6729 [69]) reveals the expected result (see Figure 7). There was little difference between the two methods for low-PMI fuels, but the PMI values calculated using the enhanced DHA method were higher for the high-PMI fuels. This result reflects the fact that the traditional DHA method identified far fewer heavy aromatics in the high-PMI fuel.

4.1.1.3. Advanced Methods. Another technique that is very useful for compound class analysis of fuels is comprehensive GC $\times$ GC. With this instrumentation, extremely high resolution can be achieved as the analytes are partially separated in one stationary phase followed by concentration and reinjection into a second phase [83]. This multidimensional chromatography is very well suited for the analysis of hydrocarbon streams as compound classes are separated primarily by carbon number or boiling point in one dimension and polarity in the second. Much more rapid analyses can be achieved compared to single-column DHA methods [84]. Compound classes such as aromatics can be completely resolved from other hydrocarbons into characteristic bands in the second-dimension chromatogram, eliminating ambiguity in retention time assignments. This is particularly useful at higher molecular weights, which are the most difficult species to separate with single-column GC. Similar to DHA methods, this analysis can be combined with MS for enhanced identification. A disadvantage of GC $\times$ GC is the relative complexity of instrumentation and data analysis, which hinders the adoption of a standardized technique.

A recently developed detector for GC, the VUV detector, allows for group-type binning without the use of multiple columns or full resolution of all compounds [도]. This technique takes advantage of the fact that most chemical species 
FIGURE 7 Correlation of PMI values calculated using the enhanced method (PMI-A) and a traditional method (PMI) [82].

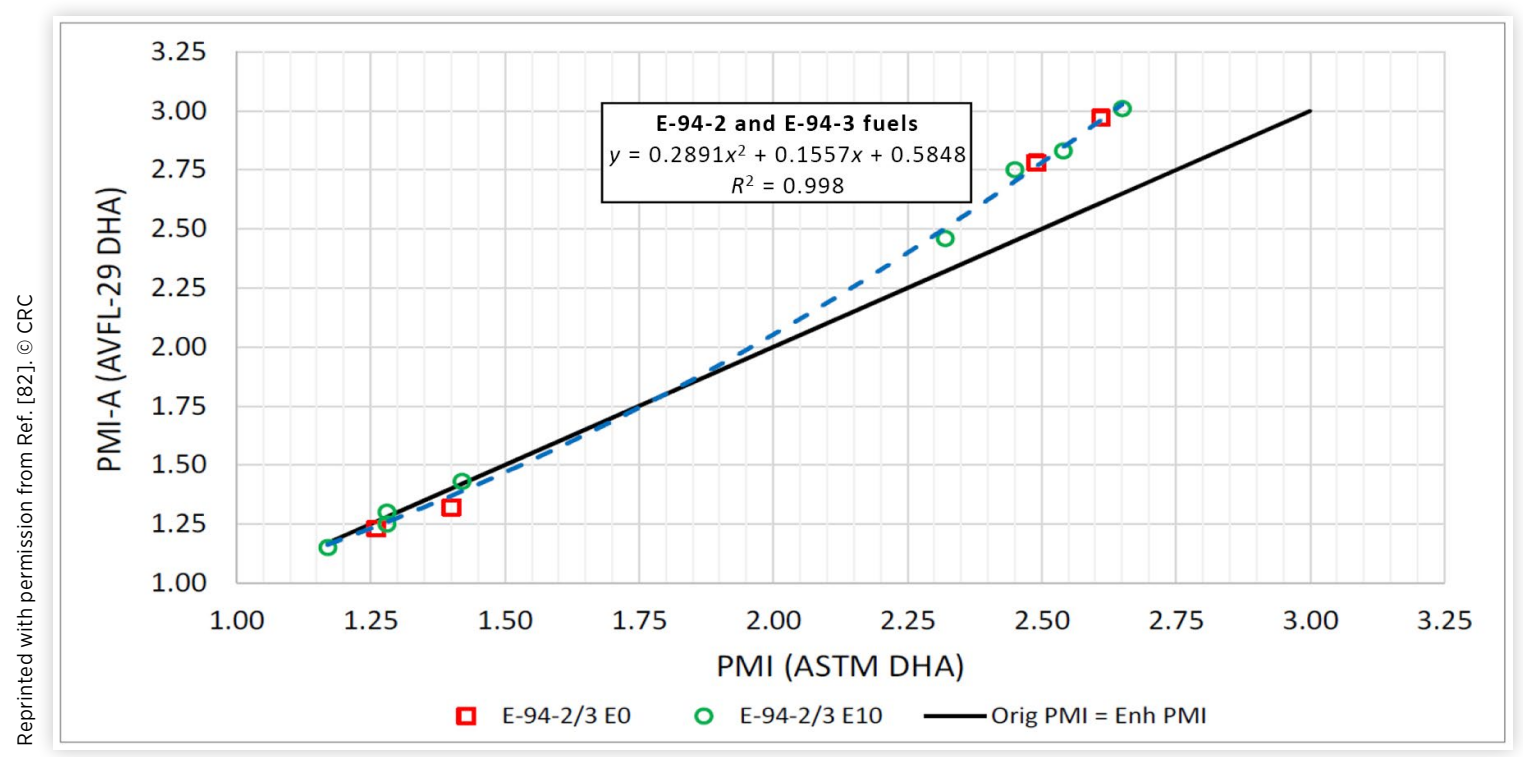

display unique absorbance spectra in the VUV range of $140-240 \mathrm{~nm}[\underline{86}]$ and the response of this detector is quantitative with a wide linear range. Given that chemical species in a class display similar absorbance spectra and response factors, with the utilization of specifically designed software for deconvolution it is possible to analyze full-range gasoline without the need for high chromatographic resolution [86]. Partially co-eluting compounds can be quantified, and hydrocarbon class positively identified, with a single detector. The current standardized method, ASTM D8071 [도], does not provide quantitation of each individual compound and generates data more closely associated with ASTM D6839 PIONA analysis [87]. However, with further development, it would be possible to provide a full DHA data set using this instrumentation. This would require a somewhat higher resolution analysis than D8071, more similar to ASTM D6729/D6730, but without the degree of resolution required for quantitation using FID. Utilizing this detector would have the advantage of spectral confirmation of compound class identifications simultaneous with robust quantitation. Providing both compound verifications and concentrations can be similarly accomplished with the enhanced DHA method described above with the use of both MS for identification and FID for quantitation. A VUV-based DHA analysis would simplify instrumentation while reducing the need for high-resolution GC. Another potential advantage of this methodology is that aromatics have a higher relative response by VUV than FID, which improves detection of low-concentration substituted naphthalenes that contribute strongly to PMI $[\underline{88}, \underline{89}]$.

4.1.2. PMI and Related Methods The concept of a PMI for gasoline was first proposed by Aikawa et al. [65]. Reasoning that both the volatility and molecular structure of fuel components play a role in particle formation, emissions testing was performed using a series of well-characterized pure compounds doped into a base fuel. $\mathrm{PN}$ emissions were found to be inversely proportional to vapor pressure and directly proportional to DBE. The latter represents the degree of unsaturation in the fuel component and is a measure of its inherent soot-formation tendency. The vapor pressure is a measure of that fuel component's tendency to evaporate and mix with air (a fully mixed stoichiometric mixture does not tend to form soot). The equation form that provided the best statistical fit to the emissions data is shown in Equation 1. The final PMI is simply the mass-weighted summation of the individual PM indices for each component of the fuel. The PMI was shown to be a reasonable predictor of PN and PM emissions for PFI and GDI vehicles. Subsequent work confirmed its applicability to a wide range of market fuels [요 (see Figure 8).

$$
\mathrm{PM}_{\text {component }}=\frac{D B E+1}{V P_{[443 \mathrm{~K}]}} \times W t
$$

where $W t$ is the weight fraction of each component (from DHA), $V P$ is the vapor pressure of each component at $443 \mathrm{~K}$, and $D B E=(2 \mathrm{C}+2-\mathrm{H}) / 2(\mathrm{C}=$ carbon number, $\mathrm{H}=$ hydrogen number).

4.1.2.1. Menger/Wittmann Index. The Menger/Wittmann (MW) index was an attempt at a more detailed index than the PMI [90]. It consists of 14 fuel parameters: density, two measures of vapor pressure (dry vapor pressure equivalent [DVPE] and absolute vapor pressure), four distillation parameters (T10, T90, T95, and FBP), total olefin and aromatic content, $\mathrm{C} 10$ aromatics, $>\mathrm{C} 10$ aromatics, $\mathrm{C} 10$ naphthenes, $>\mathrm{C} 11$ paraffins, and high-boiling-point compounds. These 14 parameters were chosen from an initial list of 200 parameters 
FIGURE 8 Relationship between PMI and measured PN on an FTP-75 cycle (weighted); 2.4-L GDI vehicle, 10 test fuels (7 market fuels from across the United States, 2 modified market fuels, and 1 test fuel) [68].

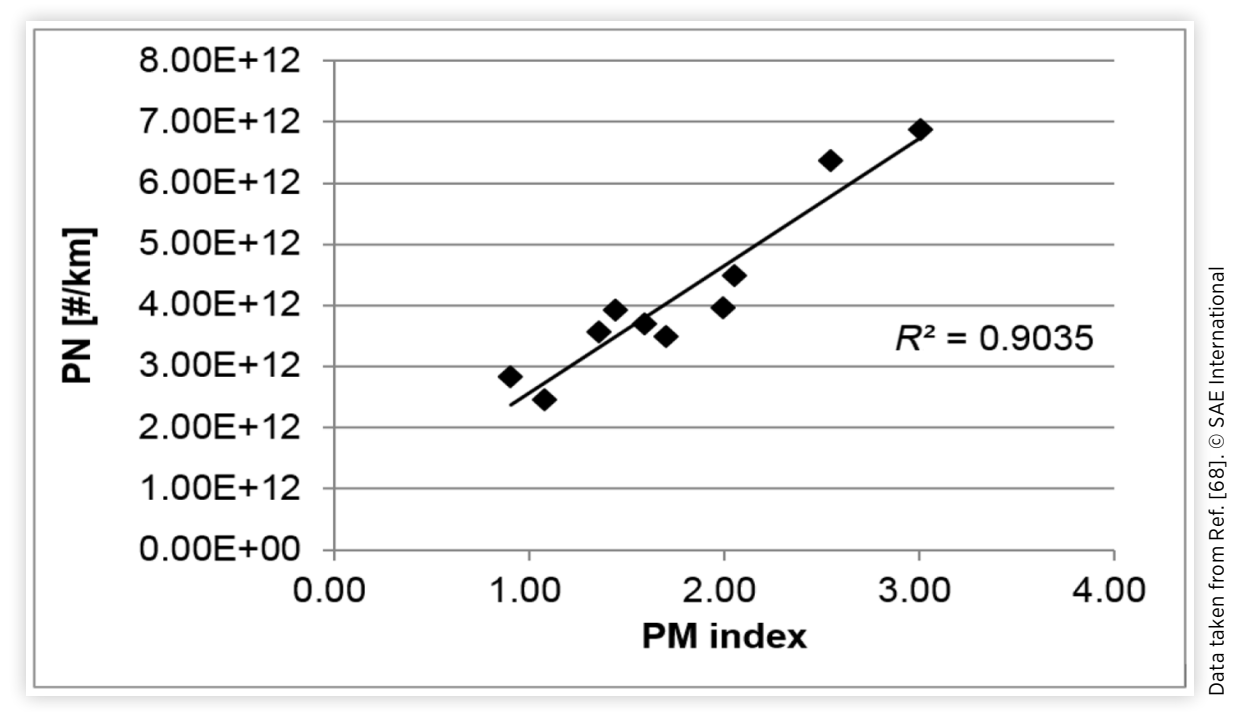

as having the greatest impact on PM emissions. The final model takes the form of the following equation:

$$
\text { MW index }=\sum_{i=1}^{14} R a \cdot G e
$$

where $R a$ is the range factor of a parameter and $G e$ is a weighting factor (either -1 or +1 , depending on whether the parameter has a positive or negative effect on PM emissions).

$R a$ is determined from the matrix of all the fuels under investigation and is effectively a ranking of each fuel parameter relative to the whole fuel matrix in $12.5 \%$ bands. $R a$ takes a value from -3.5 to +3.5 for density, DVPE, absolute vapor pressure, T10, T90, T95, FBP, and total olefin and aromatic content, and an integer value from 1 to 8 for $\mathrm{C} 10$ aromatics, $>\mathrm{C} 10$ aromatics, $\mathrm{C} 10$ naphthenes, $>\mathrm{C} 11$ paraffins, and highboiling-point compounds.

The MW index showed a higher correlation coefficient with PM emissions than the PMI, particle number index (PNI), and either simplified PMI (sPMI) in their work (see Figure 9) [90]. However, its use has not been widely reported outside this article. Although the index uses some bulk fuel properties, a DHA is still required to calculate five of its parameters, and the final calculation of the index is more complex than the PMI.

4.1.2.2. Particulate Evaluation Index. With the specific need to develop a correlation to PMI so that test fuel data could be compared across the company's various test labs, GM worked to compile multiple fuel samples over several years, along with compiling the ASTM D6729 data, PMI numbers, and other fuel properties, and looking at different types of correlations that could be easily resolved from the analysis [91]. Through that work, a new index was developed, the particulate evaluation index (PEI). Because this index requires only total aromatic concentrations at carbon numbers
7-13, it can use simpler fuel analyses than DHA, such as ASTM D6839, while maintaining a high correlation to the PMI number. It has been an effective tool for comparing test fuels and to review market fuel surveys from data sources that are using the ASTM D6839 method [91]. The final PEI number method was openly released in 2019 so that others could use and offer comments to the correlation [92]. The equation as stated in the paper is

$\mathrm{PEI}=\frac{\mathrm{C} 7+(2.5 \times \mathrm{C} 8)+(5.8 \times \mathrm{C} 9)+(4.8 \times \mathrm{C} 10)+(35.3 \times(\mathrm{C} 11+\mathrm{C} 12+\mathrm{C} 13))}{100}$

with C\# representing the volume percent aromatics at the stated carbon number. The limitation of this method, as is noted in the "Methods" section of the paper, is that the PEI number groups $\mathrm{C} 10+$ (for $\mathrm{C} 11, \mathrm{C} 12$, and $\mathrm{C} 13$ ) aromatics as a single class. This was done to accommodate using various analytical method types so that a general comparison of test fuel data could be readily compared to provide guidance to the industry $[91,93]$. There is a clear need to improve the PEI number so that it can be correlated to the Enhanced D6730 and so that the coefficients for each grouping can be clearly separated up through at least C15.

The authors of the previous work also created a new PEI equation to try to capture the impact of ethanol for a cold start condition, with the effort to try to improve the correlation of the PEI equation to engine-out emissions [93]. The evaporative cooling due to high heat of evaporation of ethanol during cold ambient temperature to fully warm up in engine cylinder combustion could substantially affect the vaporization of all the fuel species. The cooling effect is dominating when the vehicle is in the cold start and transient phase. Once the engine is warmed up and operating in closed-loop phase, all those effects are minimized. Therefore, ethanol contribution to 
FIGURE 9 PN emissions vs. indices reported by Wittmann and Menger [이].

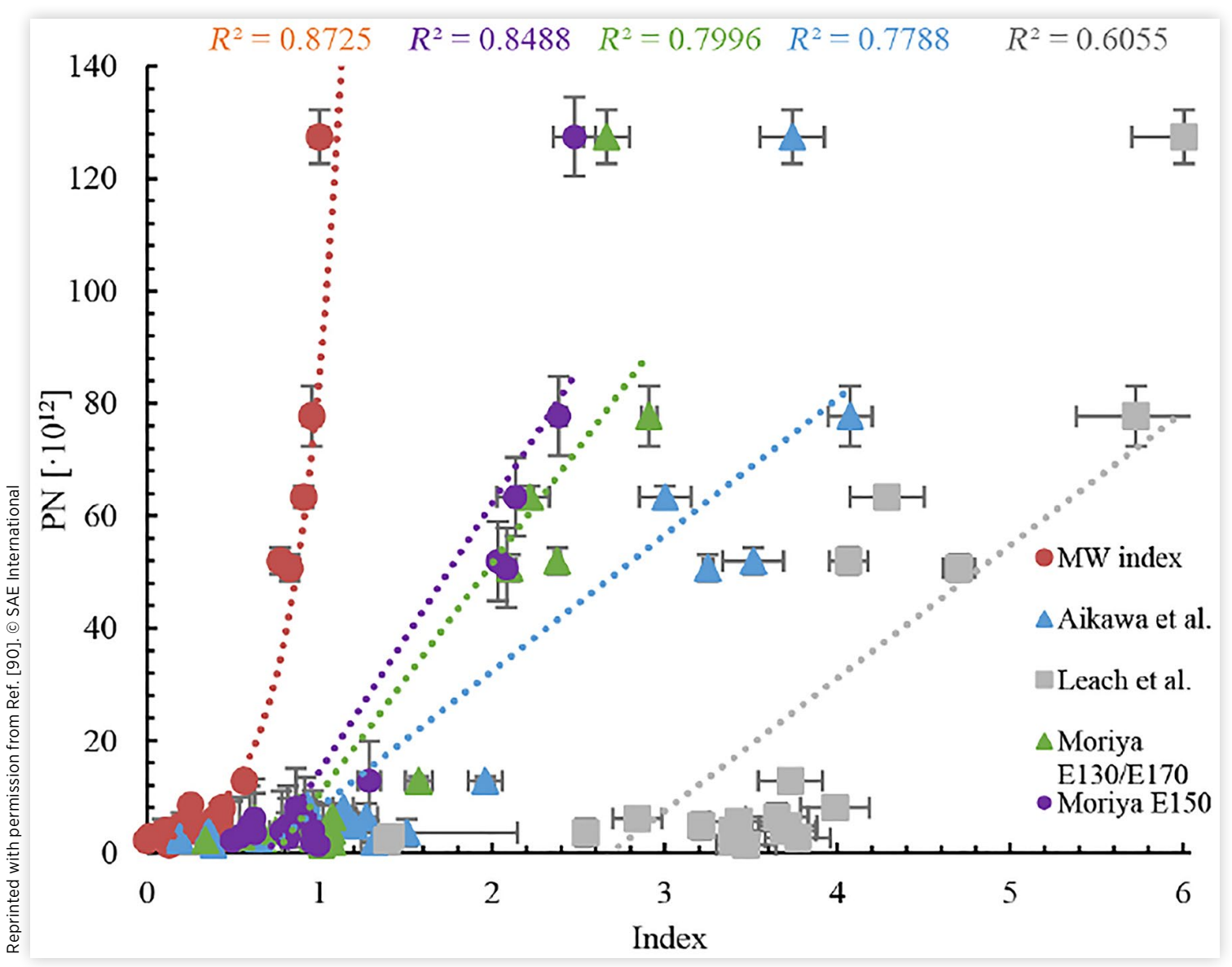

particulate emissions is largely in the early stage of vehicle operations. Those new equations are represented as follows:

$$
\mathrm{PEI}_{\mathrm{MOD}}=\sum_{i=7}^{13} A r_{i} \times C i+\frac{1}{V P\left(E t O H \text { at } 60^{\circ} \mathrm{C}\right)} V \%(E t O H)
$$

where $\sum_{i=7}^{13} A r_{i} \times C i$ is defined as $\frac{(\mathrm{C} 7+2.5 \mathrm{C} 8+14.1 \mathrm{C} 9+11.6 \mathrm{C} 10+17.7 \mathrm{C} 10>)}{100}$.

The paper provides a data set as an example of the improvement in a PEI modified equation for cold start, demonstrating that the correlation improves with this equation.

4.1.2.3. VUV PMI and VUV PMI A*. A modified version of ASTM D8071 was used to calculate a VUV PMI and a VUV PMI A*, which is a variation of the PMI concept [71]. The output data from ASTM D8071 include hydrocarbon group type totals of paraffins, isoparaffins, olefins, naphthenes, and aromatics. Benzene, toluene, ethylbenzene, xylenes, isooctane, naphthalene, methylnaphthalenes, methanol, and ethanol are also included in the modified output scope. Results are reported in mass percent and volume percent. The standard ASTM D8071 method report has been modified to break out the hydrocarbon group type totals by carbon number bins from $\mathrm{C} 3$ to $\mathrm{C} 15$ for the purpose of VUV PMI and VUV PMI A* calculations $[71,94]$. C2-naphthalenes and biphenyl are also reported. No modifications were made to the ASTM D8071 gas chromatographic parameters. From the overall method, only the D8071 data reporting has been changed.

VUV PMI and VUV PMI A* are calculated from the DBE and the vapor pressure of each reported D8071 analyte and classbased DBEs and vapor pressures. The DBE of olefins and naphthenes were set to 1 and mono-aromatics are set to 4 . Naphthalene (reported individually), methylnaphthalenes (group), and C2-naphthalenes (group) are di-aromatics with a DBE of 7. Biphenyl is a di-aromatic (reported individually) with a DBE of 8 . The vapor pressure of each hydrocarbon group-type carbon number bin was assigned an average for each carbon number based on the representative compounds from the DHA database.

VUV PMI is calculated using ethanol, the individual species, and all the hydrocarbon group types. VUV PMI A* is calculated using only the mono- and di-aromatic results.

4.1.2.4. National Renewable Energy Laboratory Index and Related Work. Although the previously discussed emissions indices have been successfully applied to a wide range of fuel compositions, some reduction in predictive quality has been noted for fuels with a high weight percent of oxygenated components. Ratcliff et al. investigated how 
interactions of ethanol with aromatic compounds affected aromatics evolution during gasoline evaporation and how this could affect particle emissions from a single-cylinder directinjection engine [34]. These researchers used an aliphatic base fuel and blended in ethanol with specific individual aromatic compounds: isopropyl benzene (cumene), p-methyl isopropyl benzene (p-cymene), and 4-t-butyl toluene. Dilution of the aromatics in gasoline by blending ethanol is expected to reduce PM. However, the results showed that a combination of ethanol's higher evaporative cooling and impact on aromatic compound vapor-liquid equilibrium could extend droplet lifetime and cause aromatics to evolve later in the droplet evaporation process than would be the case without ethanol. At high engine speed-where time for heat transfer and mixing is limited-ethanol blending caused an increase in PM emissions for the lowest-vapor-pressure aromatic. Although not evaluated in this study, similar results might be expected for blends with other high-heat-of-vaporization (HOV) materials such as methanol, isopropanol, n-propanol, and isobutanol. The PM emissions from Ratcliff et al. were not well correlated with PMI, but could be correlated with a model that included ethanol content, aromatic content, aromatic vapor pressure at $443 \mathrm{~K}$, and aromatic compound YSI (recall these fuels contained only a single aromatic compound) [프] . More generally, because the PMI is based on a weighted linear sum over the contributions from each fuel component, it cannot capture interactions between fuel components affecting PM formation due to changes in bulk fuel properties.

To address these points, researchers from the National Renewable Energy Laboratory (NREL) developed an emissions index based off the DHA and bulk fuel properties from the data of Butler et al. $[95,96]$, an extensive database of soot formation from 27 different fuel blends (including up to $40 \mathrm{~mol} \%$ ethanol) in 15 vehicles. A resulting emissions index was found via regularized linear regression to find the most important fuel properties in predicting PM formation [97]. Bulk fuel properties, including density, vapor pressure, and distillation temperatures, were combined with mole-weighted component properties, including the YSI, molecular weight, heat of vaporization, and vapor pressure at $443 \mathrm{~K}$. The resulting index included three terms-the density, temperature at $70 \%$ distillation, and a combined component-level sooting propensity term:

$$
\log \mathrm{PM} \sim a \rho+b T_{70}+c \sum_{i} \frac{Y S I_{i} \Delta H_{v a p, i}}{P_{v a p, i}(443 \mathrm{~K})} x_{i} \quad \text { Eq. (5) }
$$

where $a, b$, and $c$ are fitted slope parameters. This equation provided a strong correlation $\left(r^{2}=0.85\right)$ for the data of Butler et al. $[95,96]$, as well as earlier single-cylinder engine data of Ratcliff et al. $\left(r^{2}=0.91\right)$ [33]. The combined componentlevel term closely resembles the PMI regression, but with YSI replacing the DBE +1 descriptor and an additional contribution from the heat of vaporization. The resulting emissions index is also able to capture the effects of bulk changes in density or distillation phenomena. Despite its flexibility,
NREL's data-derived emissions index requires both a full DHA and distillation curve (in addition to density measurements) to predict relative sooting tendency. Additional experimental work to correlate fuel composition with PM emissions may therefore reveal alternative properties that can similarly be incorporated into future emissions indices.

4.1.2.5. Particulate Matter Emissions Index. Crawford and Lyons evaluated several PM and soot indices to determine their efficacy in predicting PM emission trends in the first phase of the LA92 driving cycle [82]. The original PMI was found to perform well when the evaluated fuels had the same ethanol content. However, an ethanol "bias" was noted when the PMI was applied to fuels of varying ethanol content; PM emissions from ethanol blends were consistently greater than non-oxygenated fuels of the same PMI.

To address this bias - and therefore broaden the range of fuels to which the index could be applied-work was undertaken to examine alternative mathematical formulations to the original PMI [127]. Two emission data sets were used for this activity: The EPAct data set as described in Butler et al. [96] and a more recent data set from the Coordinating Research Council (CRC) E-94-2 project [98]. The former was used to determine PFI-specific coefficients for the new formulation, and the latter was used to determine the GDI-specific coefficients. The E-94-2 GDI data benefited from the fact that the test fuels had been analyzed using the new enhanced DHA method [11]. The EPAct fuels had been analyzed using an older DHA method; the relative lack of heavy aromatic information complicated the determination of the GDI coefficients. Similar to the process described for the NREL Index above, a series of regression analyses were performed to develop the new formulation. The result was the Particulate Matter Emissions Index, PME:

$$
\mathrm{PME}=\left(\frac{43.4}{\mathrm{LHV}}\right)\left[N_{\text {TECH }} \cdot \sum_{i} \frac{w t \%_{i} \cdot y \mathrm{Term}_{i}}{V P_{i}^{\alpha=f(E t O H)}}\right] \beta
$$

The $N_{T E C H}$ is a normalization term that causes PME and PMI values to coincide at an index value of 1.00 and differs for GDI and PFI technology. The $y$ Term in the numerator represents a statistical approximation of the YSI value, i.e., the sooting potential of individual fuel components. This term can be determined by users without reference to measured or calculated YSI values. The $\alpha$ exponent in the 1/VP term depends upon the fuel's ethanol content and differs substantially between GDI and PFI technologies. This term can be modified to accommodate oxygenates other than ethanol. The $\beta$ exponent can be adjusted to accommodate DHAs of varying technology.

Studies are now underway to validate the PME using fresh data sets unrelated to PME development. Preliminary results indicate the PME to be a better predictor of emission trends than the PMI across a variety of fuels. These early data are also providing clues that will lead to further enhancements of the index. 


\subsection{Indices Based on Bulk Fuel Properties}

4.2.1. Particulate Matter Index Correlation (PMIC) Developed by Lemaire et al. in 2019, the PMIC [99] incorporates the fuel equivalent sooting index (FESI) as well as lower heating value (LHV) and HOV. The FESI [100] is based on the peak soot volume fraction measured by laserinduced incandescence of the target fuel in a diesel surrogate burned in turbulent spray flame. It can be measured for individual fuel components and then combined for a mixture as the mole-weighted average or could be measured for the bulk fuel. The PMIC equation (Equation 5) has demonstrated good results for blends of $\mathrm{C} 4$ oxygenates into a four-component gasoline surrogate. It failed, however, when applied to blends containing acetone. The use of LHV and HOV as input properties is interesting and has a physical rationale. As the equation shows, fuels with lower LHV have increased PMIC values. This may be because achieving the same engine load with a lower-LHV fuel versus a higher-LHV fuel requires a longer fuel injection duration. In a direct-injection engine, this may lead to a greater fraction of the fuel spray impinging on internal engine surfaces such as the piston, hindering fuel evaporation and creating fuel-rich regions that can generate PM. Higher-HOV fuels have higher PMIC, potentially, because if there is fuel spray impingement, higher-HOV fuels will be slower to evaporate as more energy is required, again leading to fuel-rich regions and PM formation.

$\mathrm{PMIC}=\exp \left(\left[\mathrm{FESI}^{2.34} \times \mathrm{LHV}^{-3.74} \times \mathrm{HOV}^{1.19}-\mathrm{C}_{\text {base-fuel }}\right] \times 100\right)$

where $\mathrm{C}_{\text {base-fuel }}=\mathrm{FESI}^{2.34} \times \mathrm{LHV}^{-3.74} \times \mathrm{HOV}^{1.19}$ evaluated for the base fuel without the oxygenated blendstock.

4.2.2. Particle Number Index Leach et al. $[\underline{41}, 101]$ developed the PNI (with units of $\mathrm{kPa}^{-1}$ ) as a modification of the PMI so that it might be applied without having to conduct DHA, which is not typically undertaken for gasolines. The PNI is a simplified metric to evaluate the propensity of a fuel to emit PM (specifically PN) from a GDI engine, and it takes the following form:

$$
\mathrm{PNI}=\frac{\sum_{i=1}^{n}\left[D B E_{i}+1\right] V_{i}}{D V P E(\mathrm{kPa})}
$$

In the PNI, the DBE is calculated for each subset of components in the gasoline (typically split out in the industry-standard ASTM D1319 [43] test into aromatics [DBE = 4], olefins $[\mathrm{DBE}=1]$, and saturates $[\mathrm{DBE}=0])$ by volume $\left(V_{i}\right)$ in the typical PIONA analysis. PIONA analysis is accomplished with techniques that do not require full DHA. Standardized methods have been developed that utilize specialized GC instruments with multiple chromatographic columns, traps, and switching valves that isolate hydrocarbons by class for quantification [ $\underline{87}$, 102]. These allow for more rapid analysis times and more simplified data evaluations [103]. The results of these techniques provide abundances of compound classes by carbon number, similar to those derived from DHA, but lack the level of detail as individual components are not resolved and identified. DVPE with units of kilopascal $(\mathrm{kPa})$ is the European standard for vapor pressure measurement of gasolines [104].

The PNI has been shown in multiple studies $[90,105,106]$ to be able to successfully predict PN emissions from GDI engines when restricted to market fuels, although typically with lower accuracy than other indices (notably the PMI). On the other hand, except for the sPMI (see Section 4.2.5), it relies on the least onerous (or expensive) and most commonly available input data. Making assumptions about the correlation of these parameters to more detailed fuel characteristics leads to the PNI being less useful for specialist test fuels, which deviate substantially from market-representative fuels.

\subsubsection{Particulate and Soot Correlation Equation} (PASCE) Chapman et al. determined a PMI correlation equation using the carbon/hydrogen $(\mathrm{C} / \mathrm{H})$ ratio (ASTM 5291) and the E170 point (ISO 3405) - the volume of fuel evaporated at $170^{\circ} \mathrm{C}$. The rationale for the choice of these two variables was that "diffusion combustion would be a function of the vaporization of the fuel and the specific amount of carbon in the fuel" [107]. A correlation equation was determined through linear regression models:

$$
\mathrm{PASCE}=9.37+0.517 \times \mathrm{C} / \mathrm{H}-0.11994 \times \mathrm{E} 170
$$

4.2.4. Reduced Particulate Matter Index Reduced Particulate Matter Index (RPMI) was developed by Wu et al. as a more practical alternative to PMI [108]. The index was developed utilizing the detailed analysis of 22 fuels as well as the fuel physical properties. A multivariate linear regression model was developed, and it was shown that T70 and T90 were both significantly correlated with PMI. The final version of the RPMI can be described using Equation 8. Additional independent variables were considered but not introduced in the final linear regression model, as they weakened the correlation.

$$
\mathrm{RPMI}=0.024 \times \mathrm{T} 90+0.011 \times \mathrm{T} 70-3.252
$$

\subsubsection{Simplified Particulate Matter Indices} (sPMI) Moriya proposed two variations of a "simplified" PMI based solely on distillation characteristics $[109, \underline{110}]$. Multiple bulk fuel properties were statistically tested for their ability to predict PN and PM emissions from a $2 \mathrm{~L}$ turbocharged direct-injection vehicle. The best two-factor correlation was obtained with E130 (volume of fuel evaporated at $130^{\circ} \mathrm{C}$ ) and E170, and E150 (volume of fuel evaporated at $150^{\circ} \mathrm{C}$ ) produced the best one-factor correlation. Empirically determined coefficients were added to produce a best-fit correlation to the original Honda PMI.

$$
\begin{array}{cc}
\text { sPMI v1 }=9.9241-0.0324 \times \mathrm{E} 130-0.0647 \times \mathrm{E} 170 & \text { Eq. }(11) \\
\text { sPMI v2 }=7.8511-0.0757 \times \mathrm{E} 150 & \text { Eq. }(12)
\end{array}
$$


Crawford and Lyons [르] and Leach et al. [105] found that these indices produce a reasonable correlation with measured PM and PN, respectively, for "market-representative" fuels. However, the indices struggle with fuels exhibiting a wider range of properties. This behavior was attributed to the fact that these indices do not directly consider the hydrocarbon composition of the fuel; they rely upon an assumed relationship between the distillation characteristics and fuel composition.

\subsubsection{Simplified Particle Number Index} (sPNI) The sPNI was developed by Wu et al. as a simplified way of calculating PMI [111]. The index utilizes four key fuel parameters to calculate $\mathrm{PN}$ as shown in Equation 11: T70, the final point, heavy aromatics content $(>\mathrm{C} 9)$, and the olefins content. Wu et al. tested 20 fuels from various areas at a range of typical operating modes and correlated PN with emissions during engine tests.

$$
\begin{aligned}
\mathrm{sPNI}= & 0.012 \times \mathrm{T} 70+0.048 \times \mathrm{HAC} \\
& +0.015 \times \mathrm{FBP}-0.034 \times \mathrm{OC}-2.721 \quad \text { Eq. }(13)
\end{aligned}
$$

where HAC is heavy aromatics content and OC is organic carbon.

\section{Summary and Future Work}

This article discusses the many uses and needs for a calculated index that assesses a fuel's propensity to produce particulate emissions when burned in a spark-ignition engine. In particular, these indices can be used as a tool to rate and rank fuels in terms of engine systems responses. The reference test fuels specified for emissions certification show a wide range of PM-forming tendencies across the world and, in some cases, from batch to batch. PM indices can be used to understand how these fuels are different and have potential for specifying fuels that have a consistent level of PM emissions. Similarly, given the rapid increase in RDE testing, which in some markets is conducted using market fuels, PM indices can be used to compare in-use market fuels to fuels used in vehicle certification. Along these lines, we recommend that a worldwide market fuel PMI survey be conducted to provide guidance for potential future specification of certification fuels and regulation or market fuels.

In this work, 16 indices linking fuel composition and properties to PM emissions have been identified, and these are summarized in Table A.3 in the Appendix. Five of these are based on DHA, whereas the others use distillation parameters and other properties, PIONA analysis not based on DHA, $\mathrm{C} / \mathrm{H}$ ratio, and, in one case, a measured soot-formation tendency. Thus PM indices today can be divided into two types:

- High-accuracy determinations that can be used for research and as reference or "referee" methods. To date, these are based on DHA but, in the future, could be based on the advanced analytical method that may prove to be lower cost. Such methods could be used to design fuels for fundamental research or in developing engine combustion systems and calibrations.

- Methods that provide a reasonable correlation to the "high-accuracy" PMI method(s) under practical conditions. These are based on one or more relatively easy-to-measure bulk properties, such as distillation characteristics, and may use much less resourceintensive chemical analysis methods. These PMI estimation methods could be used for routine purposes at refineries or within the fuel distribution system, or possibly to regulate fuels and limit PM.

A critical knowledge gap for future studies is a lack of large data sets with widely varying fuel properties and publicly available DHA that could be used to reveal alternative properties and to formulate an improved index, potentially eliminating the need for DHA. As future studies of gasoline effects on PM emissions are developed and published, authors, peer reviewers, and editors should recognize that the details of those studies should be made publicly available with the published work, and specifically publishing the details of the fuel analytical chemical analysis from DHAs with the GC traces and calibration details. This is so that the data can be used for validation in future studies that may develop improved indices. Any new PMI must be validated using vehicle or engine emissions data that were not used in the development of the index. Simply comparing to other PM indices, as have been done in some prior studies, is insufficient. For this purpose, fresh data sets will be needed in which a variety of well-characterized market fuels are tested in a variety of engine types.

The development of improved indices of both types will require an improved fundamental understanding of how fuel chemistry and properties affect spark-ignition engine PM emissions, as well as improved analytical methodologies for high accuracy methods.

\subsection{Basic Research Needs}

PM emissions are significantly increased when the fuel spray impinges on the piston or the cylinder wall, creating fuel films that can evaporate to form fuel-rich regions of the mixture or even burn as pool fires (diffusion flames) that generate large amounts of soot $[112,113,114]$. Fuel properties including density, dynamic viscosity, and surface tension can impact the spray penetration length and injection duration and hence have a large impact on impingement $[115,116]$. The values of these properties at the actual operating conditions of fuel injectors are largely unknown, a fact that influences both interpretation of experimental data and the ability to develop accurate spray simulations. Specific fuel properties related to spray impingement and flash boiling are generally not yet explicitly included in PM indices. Improved spray simulations that can accurately predict key spray behaviors and capture 
fluid flow and fuel evaporation during impingement are needed, along with improved models of soot formation over the range of conditions that can occur. Another factor that should be captured in simulations is flash boiling and consequent spray collapse, which reduces fuel-air mixing and increases spray penetration. Flash boiling can occur for higher-volatility fuels, especially under throttled conditions where manifold pressure may be below ambient [117, $\underline{118}, 119]$. It will require considerable effort to develop a simulation approach for sprays in GDI engines that can be accurately applied to a wide range of conventional and alternative gasoline components including oxygenates. However, at this point in the development of GDI PM indices, this approach is more likely to yield new understanding than an empirical approach.

Current PM emission indices do not adequately consider factors arising from interactions of fuel components. One example of such an interaction would be a high-HOV component (i.e., $\mathrm{C} 1$ to $\mathrm{C} 4$ alcohols) causing cooling that slows the evaporation of high-boiling aromatics. Because solutions of these alcohols in hydrocarbons are thermodynamically nonideal-their vapor-liquid equilibrium is not well described by Raoult's law-there may be other effects such as suppression of aromatic evaporation until the alcohol is evaporated $[120,121]$. There may be other interactions affecting fuel evaporation as well [34]. Studies to understand these in more detail should be conducted, and PMI approaches that can take these interactions into account need to be developed. Some studies are beginning to look at this area [97], but are hindered by a lack of adequately large and high-quality data sets. This could also include interactions in the actual combustion and soot precursor formation chemistry if these occur.

The PM indices in Table A.3 in the Appendix appear to rank fuels for particle mass and $\mathrm{PN}$ emissions equally (given the correlation between PM and PN). However, how fuels affect particle size distribution is largely unknown, and current PM indices provide no information on particle size. However, given the EU legislation's focus on particle size (moving from $23 \mathrm{~nm}$ to $10 \mathrm{~nm}$ ), this would be a useful area of future research. Clearly, fuel chemistry can affect the amount of soot formed and presumably the rate at which particles form. How this initial formation of nucleation mode particles translates into the formation of accumulation mode particles is an important area for future research.

Recent work has shown that GPFs are effective at controlling PN and PM emissions from GDI vehicles [32, 122]. Studies have also shown that the use of catalyzed GPFs can reduce PN as well as secondary organic aerosol formation [123] and can also improve conversion efficiencies for $\mathrm{CO}$ and $\mathrm{NO}_{\mathrm{x}}$ emissions under real-world conditions [124]. Although GPFs are not a focus of the current article, a number of studies have shown that oxygenates can increase the reactivity of particles trapped in a diesel particle filter $[125, \underline{126}]$, reducing the light-off temperature during regeneration. The role of fuel chemistry in the performance of GPFs has not yet been investigated.

\subsection{Research to Improve DHA-Based Indices}

5.2.1. Analytical Methods Current research on highaccuracy PM indices has relied on DHA, which provides a great deal of detail but suffers from slow analysis times and requires a high level of skill to provide accurate and reproducible results. Additionally, current DHA methods do not accurately identify the highest-molecular-weight aromatic compounds in gasoline, which may have an inordinately large impact on PM. Lab-to-lab variability can be substantial if great care is not taken to ensure peaks are correctly assigned by retention times. The inclusion of simultaneous MS analysis greatly enhances identification but increases analysis cost and complexity without reducing analysis time. An approach to improving the accuracy and precision of DHA measurements is the use of a comprehensive performance standard (for peak detection and retention time alignment) that includes ethanol and other oxygenates, and a broader range of aromatics in the GC calibration.

For the revised ASTM D6730 method (enhanced DHA), there has not been a formal inter-laboratory study for evaluation of the repeatability and reproducibility of the method since it was added by ASTM. It is important to run this study to understand the range of variation in the output compound weight percent. This could lead to further improvements to the method. Additionally, this can help determine the lab-tolab variation in the calculated PMI or other PM indices based on DHA.

Laboratories use either proprietary software (such as Hydrocarbon Expert program or Dragon DHA) or in-housedeveloped code to analyze the DHA data and calculate PMI. Each of these programs has a different method to list the compounds and may use different approaches to calculate vapor pressure. Thus a study that combines or compares data from different laboratories may find it challenging to do this on a consistent basis. We recommend the standardization of compound names and the order in which they are listed to facilitate integration. Software vendors and researchers should also be completely transparent on the source of data or estimation for the vapor pressure values. A common approach for handling the vapor pressure of unidentified isomers would also facilitate comparison, but at a minimum, researchers should completely describe how this is handled. There is also variation in the percent of sample eluted from the GC column in various studies. This seems unavoidable in that it may take significant additional time to elute all high-boiling components. Should DHA methods be used for research to inform regulations, the percent of sample analyzed should be fixed for all samples (by clearly stating the percentage of the sample identified).

A primary research direction in the coming years will be to develop indices where DHA is replaced by a less-costly method that provides much of the same information. This includes the GC-VUV methods and GC $\times$ GC methods described in this article. Another approach to improve efficiency is to focus only on the highest boiling components in 
the gasoline, which are primarily responsible for PM formation and the calculated PMI value. For example, only characterizing the $90 \%$ boiling fraction, using DHA or another method, would focus efforts on a smaller number of compounds, potentially reducing analysis times. Alternatively, the analysis could focus on an aromatic fraction removed from the gasoline by extraction, chromatography, or other methods.

5.2.2. Improving PMI Although imperfect, the original Honda PMI has been very successful at ranking fuels for the PM formation tendency in spark-ignition engines. Thus, it seems likely that research to improve DHA-based methods will focus on the analytical chemistry, as well as making modifications to PMI to improve fidelity. A major focus will be on improving the ability of a PMI-like index to accommodate ethanol and other high-HOV alcohols; as previously detailed, St. John [97] and Crawford [127] are already making progress in this area. Additionally, corrections for density, cold-start versus hot-start emissions, and other factors should be investigated.

\subsection{Research to Improve Bulk Property-Based Indices}

Indices that are based on bulk fuel properties rather than DHA can be calculated at a fraction of the cost of DHA-based indices. Bulk property-based indices are needed for use when blending fuels in the fuel distribution system, and potentially for regulatory purposes. Some of these indices have shown that good predictions of PM emissions can be made with extremely limited information (only one distillation parameter in the case of the Moriya E150 index). In general terms, the accuracy and utility of such indices break down when they are used outside of market-type fuels or, in some cases, with high levels of oxygenates, where the input parameters to these indices end up being an oversimplification of a fuel's tendency to form PM.

To date, these indices have been based largely on distillation parameters, but $\mathrm{C} / \mathrm{H}$ ratio, $\mathrm{LHV}, \mathrm{HOV}$, DVPE, and measured soot-formation tendency have all been used. With one exception, these methods have largely been purely empirical (the exception being the PNI, which is based on the same underlying theory as PMI but uses a non-DHAbased PIONA analysis). Although today we have DHA-based and largely bulk property-based indices, future indices may include aspects of both, using less-costly methods than DHA to provide the same or similar chemical information. Some of these are analytical chemistry methods that focus only on the aromatic compounds or focus on a surrogate property that aligns with the aromatic portion of the fuel. Approaches discussed previously for analyzing only the highest-boiling fractions may play a role. A better understanding of how fuel physical properties-measured at actual engine conditions-impact soot formation should be leveraged to develop theoretical concepts for bulk property-based indices.

\subsection{Summary}

In this work, we have reviewed the development of PM indices over the last decade, which has yielded substantial research interest and effort in this area. Many of these indices are now mature, and some (notably the Particulate Matter Index) are in widespread use. As PM indices reach the final development stage, they should be codified with an organization such as ASTM International, European Standards (EN), or the International Organization for Standardization. This would involve the submission of intra- and inter-laboratory PMI results, thereby establishing repeatability/reproducibility for the entire determination. Such an overall assessment of precision is needed given that multiple analytic methods are required for some indices. This would then enable these indices to play a role in future legislation, particularly important for RDE, and ultimately enable further PM emissions reductions. Such a change would not only reduce PM emissions from new vehicles but also from the existing fleet on-road today.

\section{Contact Information}

\author{
Felix Leach \\ Dept of Engineering Science \\ University of Oxford \\ Parks Rd \\ Oxford \\ OX1 3PJ \\ UK \\ felix.leach@eng.ox.ac.uk
}

\section{Definitions/Abbreviations}

ASTM - ASTM International, formerly known as the American Society for Testing and Materials

C/H - carbon/hydrogen ratio

DBE - double bond equivalent

DHA - detailed hydrocarbon analysis

DPF - diesel particulate filter

DVPE - dry vapor pressure equivalent

EC - elemental carbon

EN - European Standards

EU - European Union or Euro

EXX - temperature at which a certain volume $\%$ fuel is evaporated, for example, E100 is $100^{\circ} \mathrm{C}$

FBP - final boiling point

FESI - fuel equivalent sooting index

FID - flame ionization detection

FTP - U.S. Federal Test Procedure

GC - gas chromatography

GDI - gasoline direct injection 
GPF - gasoline particulate filter

HAC - heavy aromatic content

HOV - heat of vaporization

ISO - International Organization of Standardization

LEV - low emission vehicle

LHV - lower heating value

MS - mass spectrometry

MW - Menger/Wittmann

NREL - National Renewable Energy Laboratory

OESI - oxygen-extended sooting index

PAH - polycyclic aromatic hydrocarbon

PASCE - particulate and soot correlation equation

PEI - particulate evaluation index

PEMS - portable emissions measurement system

PFI - port fuel injection

PIONA - paraffins, isoparaffins, olefins, naphthenes, and aromatics

PM - particulate matter

PMI - particulate matter index

PMIC - particulate matter index correlation

PMP - Particle Measurement Programme

PN - particle number

PNI - particle number index

POA - primary organic aerosols

RDE - Real Driving Emissions

RPMI - reduced particulate matter index

sPMI - simplified particulate matter index

sPNI - simplified particle number index

SULEV - Super ultra-low emission vehicle

T10 - temperature at which $10 \%$ of a fuel has evaporated

T70 - temperature at which $70 \%$ of a fuel has evaporated

T90 - temperature at which $90 \%$ of a fuel has evaporated

T95 - temperature at which 95\% of a fuel has evaporated

TSI - threshold sooting index

ULEV - ultra-low emission vehicle

VUV - vacuum ultraviolet

WLTP - Worldwide-Harmonized Light Vehicle Test Procedure

YSI - yield sooting index

\section{References}

1. EPA, "The 2020 EPA Automotive Trends Report: Greenhouse Gas Emissions, Fuel Economy, and Technology Since 1975," EPA-420-R-21-003, 2021, https://www.epa.gov/automotivetrends/download-automotive-trends-report.
2. Raza, M. et al., "A Review of Particulate Number (PN) Emissions from Gasoline Direct Injection (GDI) Engines and Their Control Techniques," Energies 11, no. 6 (2018): 1417, https://doi.org/10.3390/en11061417.

3. Leach, F. et al., "Particulate Emissions from a Highly Boosted Gasoline Direct Injection Engine," International Journal of Engine Research 19, no. 3 (2018): 347-359, https:// doi.org/10.1177/1468087417710583.

4. Reprinted (adapted) with permission from Saliba, G. et al., "Comparison of Gasoline Direct-Injection (GDI) and Port Fuel Injection (PFI) Vehicle Emissions: Emission Certification Standards, Cold-Start, Secondary Organic Aerosol Formation Potential, and Potential Climate Impacts," Environmental Science \& Technology 51, no. 11 (2017): 6542-6552, https://doi.org/10.1021/acs.est.6b06509. Copyright (2017) American Chemical Society.

5. Braisher, M., Stone, R., and Price, P., "Particle Number Emissions from a Range of European Vehicles," SAE Technical Paper 2010-01-0786, 2010, https://doi. org/10.4271/2010-01-0786.

6. Mamakos, A., Martini, G., and Manfredi, U., "Assessment of the Legislated Particle Number Measurement Procedure for a Euro 5 and a Euro 6 Compliant Diesel Passenger Cars under Regulated and Unregulated Conditions," Journal of Aerosol Science 55 (2013): 31-47, https://doi.org/10.1016/j. jaerosci.2012.07.012.

7. Demuynck, J., Favre, C., Bosteels, D., Hamje, H. et al., "RealWorld Emissions Measurements of a Gasoline Direct Injection Vehicle without and with a Gasoline Particulate Filter," SAE Technical Paper 2017-01-0985, 2017, https://doi. org/10.4271/2017-01-0985.

8. Andersson, J., May, J., Favre, C., Bosteels, D. et al., "On-Road and Chassis Dynamometer Evaluations of Emissions from Two Euro 6 Diesel Vehicles," SAE Int. J. Fuels Lubr. 7, no. 3 (2014): 919-934, https://doi.org/10.4271/2014-01-2826.

9. Yang, J. et al., "Impacts of Gasoline Aromatic and Ethanol Levels on the Emissions from GDI Vehicles: Part 2. Influence on Particulate Matter, Black Carbon, and Nanoparticle Emissions," Fuel 252 (2019): 812-820, https://doi. org/10.1016/j.fuel.2019.04.144.

10. Yang, J. et al., "Gasoline Particulate Filters as an Effective Tool to Reduce Particulate and Polycyclic Aromatic Hydrocarbon Emissions from Gasoline Direct Injection (GDI) Vehicles: A Case Study with Two GDI Vehicles," Environmental Science \& Technology 52, no. 5 (2018): 32753284, https://doi.org/10.1021/acs.est.7b05641.

11. Lubkowitz, J. and Meneghini, R., "Enhanced Speciation of Gasoline," CRC Report No. AVFL-29, 2018, http://crcsite. wpengine.com/wp-content/uploads/2019/05/CRC-ProjectAVFL-29-Final-Report June-2018-1.pdf.

12. Coordinating Research Council, “Annual Report," 2020, http://3mpm51mqb7ryj2j12n04r01b-wpengine.netdna-ssl. com/wp-content/uploads/2020/10/Final-2020-CRC-AnnualReport.pdf.

13. Economic Commission for Europe of the United Nations (UN/ECE), "Regulation No. 83-Uniform Provisions 
Concerning the Approval of Vehicles with Regard to the Emission of Pollutants according to Engine Fuel Requirements," 2006, https://op.europa.eu/en/publicationdetail/-/publication/2f8f0ce5-66fb-4a38-ae68-558ae1b04a5f/ language-en.

14. US Environmental Protection Agency, " 40 CFR $\$ 1065-$ Engine-Testing Procedures,” 2005, https://www.ecfr.gov/ cgi-bin/text-idx?tpl=/ecfrbrowse/Title40/40cfr1065 main 02.tpl.

15. Hu, S., Zhang, S., Sardar, S., Chen, S. et al., "Evaluation of Gravimetric Method to Measure Light-Duty Vehicle Particulate Matter Emissions at Levels below One Milligram per Mile (1 mg/mile)," SAE Technical Paper 2014-01-1571, 2014, https://doi.org/10.4271/2014-01-1571.

16. Andersson, J. et al., "Particle Measurement Programme (PMP) Light-Duty Inter-Laboratory Correlation Exercise (ILCE_LD)," Final Report, European Commission Joint Research Centre Institute for Environment and Sustainability, 2007.

17. Giechaskiel, B., "Real Driving Emissions (RDE) Particle Number (PN) Portable Measurement Systems (PEMS) Calibration," JRC Technical Papers, 2018, https://op.europa. eu/en/publication-detail/-/publication/1cd9b5ef-07cd-11e8b8f5-01aa75ed71a1.

18. Giechaskiel, B., Manfredi, U., and Martini, G., "Engine Exhaust Solid Sub-23 nm Particles: I. Literature Survey," SAE Int. J. Fuels Lubr. 7, no. 3 (2014): 950-964, https://doi. org/10.4271/2014-01-2834.

19. Giechaskiel, B. et al., "Investigation of Vehicle Exhaust Sub$23 \mathrm{~nm}$ Particle Emissions," Aerosol Science and Technology 51, no. 5 (2017): 626-641, https://doi.org/10.1080/02786826.20 17.1286291.

20. Alanen, J. et al., "The Formation and Physical Properties of the Particle Emissions from a Natural Gas Engine," Fuel 162 (2015): 155-161, https://doi.org/10.1016/j.fuel.2015.09.003.

21. Rönkkö, T. et al., "Vehicle Engines Produce Exhaust Nanoparticles Even When Not Fueled," Environmental Science \& Technology 48, no. 3 (2014): 2043-2050, https://doi. org/10.1021/es405687m.

22. Leach, F., Lewis, A., Akehurst, S., Turner, J. et al., "Sub$23 \mathrm{~nm}$ Particulate Emissions from a Highly Boosted GDI Engine," SAE Technical Paper 2019-24-0153, 2019, https:// doi.org/10.4271/2019-24-0153.

23. Samaras, Z., Andersson, J., Bergmann, A., Hausberger, S. et al., "Measuring Automotive Exhaust Particles Down to 10 nm," SAE Int. J. Adv. \& Curr. Prac. in Mobility 3, no. 1 (2021): 539-550, https://doi.org/10.4271/2020-01-2209.

24. PEMs4Nano, accessed March 7, 2019, http://www. pems4nano.eu.

25. Down To Ten, accessed March 7, 2019, http://www. downtoten.com/.

26. SUREAL-23, accessed March 7, 2019, http://sureal-23.cperi. certh.gr.
27. Khalek, I., Bougher, T., and Jetter, J., "Particle Emissions from a 2009 Gasoline Direct Injection Engine Using Different Commercially Available Fuels," SAE Int. J. Fuels Lubr. 3, no. 2 (2010): 623-637, https://doi.org/10.4271/201001-2117.

28. Maricq, M., Szente, J., Loos, M., and Vogt, R., "Motor Vehicle PM Emissions Measurement at LEV III Levels," SAE Int. J. Engines 4, no. 1 (2011): 597-609, https://doi.org/10.4271/2011$\underline{01-0623}$.

29. Maricq, M.M. et al., "Influence of Mileage Accumulation on the Particle Mass and Number Emissions of Two Gasoline Direct Injection Vehicles," Environmental Science \& Technology 47, no. 20 (2013): 11890-11896, https://doi. org/10.1021/es402686z.

30. Chan, T., "Black Carbon Particle Emissions from GDI Vehicles Operating on Different Fuels," in Workshop on Effects of Fuel Composition on PM, Chicago, 2016, https:// www.healtheffects.org/sites/default/files/Chan-Ethanol fuel effect on BC emissions.pdf.

31. Yamada, H., Inomata, S., and Tanimoto, H., "Particle and VOC Emissions from Stoichiometric Gasoline Direct Injection Vehicles and Correlation between Particle Number and Mass Emissions," Emission Control Science and Technology 3, no. 2 (2017): 135-141, https://doi.org/10.1007/ s40825-016-0060-0.

32. Joshi, A. and Johnson, T.V., "Gasoline Particulate Filters-A Review," Emission Control Science and Technology 4, no. 4 (2018): 219-239, https://doi.org/10.1007/ s40825-018-0101-y.

33. Ratcliff, M., Burton, J., Sindler, P., Christensen, E. et al., "Knock Resistance and Fine Particle Emissions for Several Biomass-Derived Oxygenates in a Direct-Injection SparkIgnition Engine," SAE Int. J. Fuels Lubr. 9, no. 1 (2016): 59-70, https://doi.org/10.4271/2016-01-0705.

34. Ratcliff, M.A. et al., "Impact of Ethanol Blending into Gasoline on Aromatic Compound Evaporation and Particle Emissions from a Gasoline Direct Injection Engine," Applied Energy 250 (2019): 1618-1631, https://doi.org/10.1016/j. apenergy.2019.05.030.

35. EU, Commission Regulation (EU) 2017/1151, 2017.

36. Giechaskiel, B. et al., "Framework for the Assessment of PEMS (Portable Emissions Measurement Systems) Uncertainty," Environmental Research 166 (2018): 251-260, https://doi.org/10.1016/j.envres.2018.06.012.

37. Mock, P., "Real-Driving Emissions Test Procedure for Exhaust Gas Pollutant Emissions of Cars and Light Commercial Vehicles in Europe," ICCT Policy Update, 2017, https://theicct.org/publications/real-drivingemissions-test-procedure-exhaust-gas-pollutant-emissionscars-and-light.

38. Clairotte, M. et al., "Light-Duty Vehicles Emissions Testing-Contribution to the EU Market Surveillance: Testing Protocols and Vehicle Emissions Performance," JRC Science for Policy Report, Joint Research Centre, 2018, 
https://op.europa.eu/en/publication-detail/-/ publication/939fdd7f-93a3-11e8-8bc1-01aa75ed71a1/ language-en.

39. Engeljehringer, K., "Emission Regulation Trends: Overcoming BS6 \& RDE Challenges with 2020 Getting Closer," in AVL India Seminar, May 2018, https://www.avl. com/documents/10138/8665616/02+AVL+India+Seminar+M ay+2018 Regulation+Trends_Engeljehringer.pdf.

40. Ball, D., Meng, X., and Weiwei, G., "Vehicle Emission Solutions for China $6 \mathrm{~b}$ and Euro 7," SAE Technical Paper 2020-01-0654, 2020, https://doi.org/10.4271/2020-01-0654.

41. Leach, F. et al., "Predicting the Particulate Matter Emissions from Spray-Guided Gasoline Direct-Injection Spark Ignition Engines," Proceedings of the Institution of Mechanical Engineers, Part D: Journal of Automobile Engineering 231, no. 6 (2017): 717-730, https://doi. org/10.1177/0954407016657453.

42. US Environmental Protection Agency, " 40 CFR $₫ 80.161-$ Detergent Additive Certification Program," 1996, https:// www.govinfo.gov/content/pkg/CFR-2014-title40-vol17/pdf/ CFR-2014-title40-vol17-sec80-161.pdf.

43. Top Tier Detergent Gasoline Deposit Control Performance Standard, "Revision F," 2019, https://www.toptiergas.com/ documents/18/TOP TIER Detergent_Gasoline Performance Standard revF 2019-12.pdf.

44. Monroe, R., Studzinski, W., Parsons, J., La, C. et al., "Engine Particulate Emissions as a Function of Gasoline Deposit Control Additive," SAE Int. J. Fuels Lubr. 14, no. 1 (2021): 3-11, https://doi.org/10.4271/04-14-01-0001.

45. Chapman, E., Studzinski, W., Monroe, R., Tolou, A. et al., "Impact of Fuel Detergent Type and Concentration on the Rate and Severity of Stochastic Preignition in a Turbocharged Spark Ignition Direct Injection Gasoline Engine," SAE Technical Paper 2021-01-0490, 2021, https:// doi.org/10.4271/2021-01-0490.

46. Richter, H. and Howard, J.B., "Formation of Polycyclic Aromatic Hydrocarbons and Their Growth to Soot-A Review of Chemical Reaction Pathways," Progress in Energy and Combustion Science 26, no. 4 (2000): 565-608, https:// doi.org/10.1016/S0360-1285(00)00009-5.

47. Barrientos, E.J. et al, "Effects of Oxygenates Molecular Structure on the Sooting Tendency and PM Emissions of Ethanol-Gasoline and Biodiesel-Diesel Blends," in ASME 2012 International Mechanical Engineering Congress and Exposition, Houston, TX, USA, 2012, https://doi. org/10.1115/IMECE2012-85745.

48. Olson, D.B., Pickens, J.C., and Gill, R.J., "The Effects of Molecular Structure on Soot Formation II," Diffusion flames. Combustion and Flame 62, no. 1 (1985): 43-60, https://doi. org/10.1016/0010-2180(85)90092-6.

49. Frenklach, M. and Wang, H., "Detailed Modeling of Soot Particle Nucleation and Growth," Symposium (International) on Combustion 23, no. 1 (1991): 1559-1566, https://doi. org/10.1016/S0082-0784(06)80426-1.
50. Frenklach, M., "Reaction Mechanism of Soot Formation in Flames," Physical Chemistry Chemical Physics 4, no. 11 (2002): 2028-2037, https://doi.org/10.1039/B110045A.

51. Xu, F., Sunderland, P.B., and Faeth, G.M., "Soot Formation in Laminar Premixed Ethylene/Air Flames at Atmospheric Pressure," Combustion and Flame 108, no. 4 (1997): 471-493, https://doi.org/10.1016/S0010-2180(96)00200-3.

52. Appel, J., Bockhorn, H., and Frenklach, M., "Kinetic Modeling of Soot Formation with Detailed Chemistry and Physics: Laminar Premixed Flames of C2 Hydrocarbons," Combustion and Flame 121, no. 1 (2000): 122-136, https://doi. org/10.1016/S0010-2180(99)00135-2.

53. Blanquart, G., Pepiot-Desjardins, P., and Pitsch, H., "Chemical Mechanism for High Temperature Combustion of Engine Relevant Fuels with Emphasis on Soot Precursors," Combustion and Flame 156, no. 3 (2009): 588-607, https:// doi.org/10.1016/j.combustflame.2008.12.007.

54. Calcote, H.F. and Manos, D.M., "Effect of Molecular Structure on Incipient Soot Formation," Combustion and Flame 49, no. 1-3 (1983): 289-304, https://doi. org/10.1016/0010-2180(83)90172-4.

55. Hunt, R.A., "Relation of Smoke Point to Molecular Structure," Industrial \& Engineering Chemistry 45, no. 3 (1953): 602-606, https://doi.org/10.1021/ie50519a039.

56. Olson, D.B. and Pickens, J.C., "The Effects of Molecular Structure on Soot Formation, I. Soot Thresholds in Premixed Flames," Combustion and Flame 57, no. 2 (1984): 199-208, https://doi.org/10.1016/0010-2180(84)90057-9.

57. Pepiot-Desjardins, P. et al., "Structural Group Analysis for Soot Reduction Tendency of Oxygenated Fuels," Combustion and Flame 154, no. 1 (2008): 191-205, https://doi. org/10.1016/j.combustflame.2008.03.017.

58. Barrientos, E.J., Lapuerta, M., and Boehman, A.L., "Group Additivity in Soot Formation for the Example of C-5 Oxygenated Hydrocarbon Fuels," Combustion and Flame 160, no. 8 (2013): 1484-1498, https://doi.org/10.1016/j. combustflame.2013.02.024.

59. ASTM International, "Standard Test Method for Smoke Point of Kerosine and Aviation Turbine Fuel," ASTM D1322-08, West Conshohocken, PA, 2008.

60. McEnally, C.S. and Pfefferle, L.D., "Improved Sooting Tendency Measurements for Aromatic Hydrocarbons and Their Implications for Naphthalene Formation Pathways," Combustion and Flame 148, no. 4 (2007): 210-222, https:// doi.org/10.1016/j.combustflame.2006.11.003.

61. Das, D.D. et al., "Sooting Tendencies of Diesel Fuels, Jet Fuels, and Their Surrogates in Diffusion Flames," Fuel 197 (2017): 445-458, https://doi.org/10.1016/j.fuel.2017.01.099.

62. Das, D.D. et al., "Measuring and Predicting Sooting Tendencies of Oxygenates, Alkanes, Alkenes, Cycloalkanes, and Aromatics on a Unified Scale," Combustion and Flame 190 (2018): 349-364, https://doi.org/10.1016/j. combustflame.2017.12.005. 
63. McEnally, C.S. and Pfefferle, L.D., "Sooting Tendencies of Oxygenated Hydrocarbons in Laboratory-Scale Flames," Environmental Science \& Technology 45, no. 6 (2011): 2498-2503, https://doi.org/10.1021/es103733q.

64. Das, D.D., McEnally, C.S., and Pfefferle, L.D., "Sooting Tendencies of Unsaturated Esters in Nonpremixed Flames," Combustion and Flame 162, no. 4 (2015): 1489-1497, https:// doi.org/10.1016/j.combustflame.2014.11.012.

65. Aikawa, K., Sakurai, T., and Jetter, J., "Development of a Predictive Model for Gasoline Vehicle Particulate Matter Emissions," SAE Int. J. Fuels Lubr. 3, no. 2 (2010): 610-622, https://doi.org/10.4271/2010-01-2115.

66. Li, L. and Sunderland, P.B., "An Improved Method of Smoke Point Normalization," Combustion Science and Technology 184, no. 6 (2012): 829-841, https://doi.org/10.1080/00102202. 2012.670333

67. St. John, P.C. et al., "A Quantitative Model for the Prediction of Sooting Tendency from Molecular Structure," Energy \& Fuels 31, no. 9 (2017): 9983-9990, https://doi.org/10.1021/acs. energyfuels.7b00616.

68. Aikawa, K. and Jetter, J.J., "Impact of Gasoline Composition on Particulate Matter Emissions from a Direct-Injection Gasoline Engine: Applicability of the Particulate Matter Index," International Journal of Engine Research 15, no. 3 (2014): 298-306, https://doi.org/10.1177/1468087413481216.

69. ASTM International, "Standard Test Method for Determination of Individual Components in Spark Ignition Engine Fuels by 100 Metre Capillary High Resolution Gas Chromatography," ASTM D6729-14, West Conshohocken, PA, 2014.

70. ASTM International, "Standard Test Method for Determination of Individual Components in Spark Ignition Engine Fuels by 100-Metre Capillary (with Precolumn) High-Resolution Gas Chromatography," ASTM D6730-19, West Conshohocken, PA, 2019.

71. Cochran, J. et al., Estimating Particulate Matter Index for Gasoline with Fast Gas Chromatography-Vacuum Ultraviolet Spectroscopy, in Gulf Coast Conference, Galveston, TX, USA, 2018.

72. Yao, C. et al., "Experimental Study of the Effect of Heavy Aromatics on the Characteristics of Combustion and Ultrafine Particle in DISI Engine," Fuel 203 (2017): 290-297, https://doi.org/10.1016/j.fuel.2017.04.080.

73. Fatouraie, M., Frommherz, M., Mosburger, M., Chapman, E. et al., "Investigation of the Impact of Fuel Properties on Particulate Number Emission of a Modern Gasoline Direct Injection Engine," SAE Technical Paper 2018-01-0358, 2018, https://doi.org/10.4271/2018-01-0358.

74. Canadian General Standards Board, "Methods of Testing Petroleum and Associated Products Standard Test Method for the Identification of Components in Automotive
Gasoline Using Gas Chromatography," National Standard of Canada No. 14.3-2016, 2016, publications.gc.ca/ pub?id $=9.838469 \& s l=0$.

75. Sanders, W.N. and Maynard, J.B., "Capillary Gas Chromatographic Method for Determining the C3-C12 Hydrocarbons in Full-Range Motor Gasolines," Analytical Chemistry 40, no. 3 (1968): 527-535, https://doi.org/10.1021/ ac60259a046.

76. ASTM International, "Standard Test Method for Determination of Individual Components in Spark Ignition Engine Fuels by 50-Metre Capillary High Resolution Gas Chromatography," ASTM D6733-01(2016), West Conshohocken, PA, 2016.

77. ASTM International, "Standard Test Method for Detailed Analysis of Petroleum Naphthas through n-Nonane by Capillary Gas Chromatography," ASTM D5134-13(2017), West Conshohocken, PA, 2017.

78. Scanlon, J.T. and Willis, D.E., "Calculation of Flame Ionization Detector Relative Response Factors Using the Effective Carbon Number Concept," Journal of Chromatographic Science 23, no. 8 (1985): 333-340, https:// doi.org/10.1093/chromsci/23.8.333.

79. Ghosh, P., Hickey, K.J., and Jaffe, S.B., "Development of a Detailed Gasoline Composition-Based Octane Model," Industrial \& Engineering Chemistry Research 45, no. 1 (2006): 337-345, https://doi.org/10.1021/ie050811h.

80. Spieksma, W., "Prediction of ASTM Method D86 Distillation of Gasolines and Naphthas according to the FugacityFilmmodel from Gas Chromatographic Detailed Hydocarbon Analysis," Journal of Chromatographic Science 36, no. 9 (1998): 467-475, https://doi.org/10.1093/ chromsci/36.9.467.

81. Chupka, G., Christensen, E., Fouts, L., Alleman, T. et al., "Heat of Vaporization Measurements for Ethanol Blends Up To 50 Volume Percent in Several Hydrocarbon Blendstocks and Implications for Knock in SI Engines," SAE Int. J. Fuels Lubr. 8, no. 2 (2015): 251-263, https://doi.org/10.4271/2015-01-0763.

82. Crawford, R. and Lyons, J., "Assessment of the Relative Accuracy of the PM Index and Related Methods," CRC Report No. RW-107, 2019, http://crcsite.wpengine.com/wp-content/ uploads/2019/05/CRC-RW-107-Final-Report 2019-04-15.pdf.

83. Schoenmakers, P.J. et al., "Comparison of Comprehensive Two-Dimensional Gas Chromatography and Gas Chromatography-Mass Spectrometry for the Characterization of Complex Hydrocarbon Mixtures," Journal of Chromatography A 892, no. 1 (2000): 29-46, https://doi.org/10.1016/S0021-9673(00)00744-5.

84. Seeley, J.V. et al., "Microfluidic Deans Switch for Comprehensive Two-Dimensional Gas Chromatography," Analytical Chemistry 79, no. 5 (2007): 1840-1847, https://doi. org/10.1021/ac061881g. 
85. ASTM International, "Standard Test Method for Determination of Hydrocarbon Group Types and Select Hydrocarbon and Oxygenate Compounds in Automotive Spark-Ignition Engine Fuel Using Gas Chromatography with Vacuum Ultraviolet Absorption Spectroscopy Detection (GC-VUV)," ASTM D8071-19, West Conshohocken, PA, 2019.

86. Walsh, P., Garbalena, M., and Schug, K.A., "Rapid Analysis and Time Interval Deconvolution for Comprehensive Fuel Compound Group Classification and Speciation Using Gas Chromatography-Vacuum Ultraviolet Spectroscopy," Analytical Chemistry 88, no. 22 (2016): 11130-11138, https:// doi.org/10.1021/acs.analchem.6b03226.

87. ASTM International, "Standard Test Method for Hydrocarbon Types, Oxygenated Compounds, and Benzene in Spark Ignition Engine Fuels by Gas Chromatography," ASTM D6839-18, West Conshohocken, PA, 2018.

88. Santos, I.C. and Schug, K.A., "Recent Advances and Applications of Gas Chromatography Vacuum Ultraviolet Spectroscopy," Journal of Separation Science 40, no. 1 (2017): 138-151, https://doi.org/10.1002/jssc.201601023.

89. Dunkle, M.N. et al., "Quantification of the Composition of Liquid Hydrocarbon Streams: Comparing the GC-VUV to DHA and GCxGC," Journal of Chromatography A 1587 (2019): 239-246, https://doi.org/10.1016/j. chroma.2018.12.026.

90. Wittmann, J. and Menger, L., "Novel Index for Evaluation of Particle Formation Tendencies of Fuels with Different Chemical Compositions," SAE Int. J. Fuels Lubr. 10, no. 3 (2017): 690-697, https://doi.org/10.4271/2017-01-9380.

91. Chapman, E., Winston-Galant, M., Geng, P., and Konzack, A., "Global Market Gasoline Range Fuel Review Using Fuel Particulate Emission Correlation Indices," SAE Technical Paper 2016-01-2251, 2016, https://doi.org/10.4271/2016-01$\underline{2251}$.

92. Chapman, E., Winston-Galant, M., Geng, P., and Pryor, S., "Development of an Alternative Predictive Model for Gasoline Vehicle Particulate Matter and Particulate Number," SAE Technical Paper 2019-01-1184, 2019, https:// doi.org/10.4271/2019-01-1184.

93. Chapman, E., Geng, P., and Konzack, A., "Global Market Gasoline Quality Review: Five Year Trends in Particulate Emission Indices," SAE Technical Paper 2021-01-0623, 2021, https://doi.org/10.4271/2021-01-0623.

94. Chapman, E., Salyers, J., Wispinski, D., Scussel, M. et al., "Comparison of the Particulate Matter Index and Particulate Evaluation Index Numbers Calculated by Detailed Hydrocarbon Analysis by Gas Chromatography (Enhanced ASTM D6730) and Vacuum Ultraviolet Paraffin, Isoparaffin, Olefin, Naphthene, and Aromatic Analysis (ASTM D8071)," SAE Technical Paper 2021-01-5070, 2021, https://doi. org/10.4271/2021-01-5070.
95. Sobotowski, R., Butler, A., and Guerra, Z., "A Pilot Study of Fuel Impacts on PM Emissions from Light-Duty Gasoline Vehicles," SAE Int. J. Fuels Lubr. 8, no. 1 (2015): 214-233, https://doi.org/10.4271/2015-01-9071.

96. Butler, A., Sobotowski, R., Hoffman, G., and Machiele, P., "Influence of Fuel PM Index and Ethanol Content on Particulate Emissions from Light-Duty Gasoline Vehicles," SAE Technical Paper 2015-01-1072, 2015, https://doi. org/10.4271/2015-01-1072.

97. St. John, P.C., Kim, S., and McCormick, R.L., "Development of a Data-Derived Sooting Index Including OxygenContaining Fuel Components," Energy \& Fuels 33, no. 10 (2019): 10290-10296, https://doi.org/10.1021/acs. energyfuels.9b02458.

98. Morgan, P. et al., "Evaluation and Investigation of Fuel Effects on Gaseous and Particulate Emissions on SIDI InUse Vehicles," CRC Report No. E-94-2, 2017, http://crcsite. wpengine.com/wp-content/uploads/2019/05/CRC 2017-321_03-20955_E94-2FinalReport-Rev1b.pdf.

99. Lemaire, R., Boudreau, A., and Seers, P., "Performance and Emissions of a DISI Engine Fueled with Gasoline/Ethanol and Gasoline/C-4 Oxygenate Blends-Development of a PM Index Correlation for Particulate Matter Emission Assessment," Fuel 241 (2019): 1172-1183, https://doi. org/10.1016/j.fuel.2018.12.007.

100. Lemaire, R., Lapalme, D., and Seers, P., "Analysis of the Sooting Propensity of C-4 and C-5 Oxygenates: Comparison of Sooting Indexes Issued from Laser-Based Experiments and Group Additivity Approaches," Combustion and Flame 162, no. 9 (2015): 3140-3155, https://doi.org/10.1016/j. combustflame.2015.03.018

101. Leach, F., Stone, R., and Richardson, D., “The Influence of Fuel Properties on Particulate Number Emissions from a Direct Injection Spark Ignition Engine," SAE Technical Paper 2013-01-1558, 2013, https://doi.org/10.4271/2013-01$\underline{1558}$.

102. ASTM International, "Standard Test Method for Determination of Benzene, Toluene, Ethylbenzene, $\mathrm{p} / \mathrm{m}$ Xylene, o-Xylene, C9 and Heavier Aromatics, and Total Aromatics in Finished Gasoline by Gas Chromatography," ASTM D5580-15(2020), West Conshohocken, PA, 2020.

103. Kosal, N., Bhairi, A., and Ali, M.A., "Determination of Hydrocarbon Types in Naphthas, Gasolines and Kerosenes: A Review and Comparative Study of Different Analytical Procedures," Fuel 69, no. 8 (1990): 1012-1019, https://doi. org/10.1016/0016-2361(90)90013-G

104. EN 13016:2007, "Liquid Petroleum Products. Vapour Pressure. Determination of Air Saturated Vapour Pressure (ASVP) and Calculated Dry Vapour Pressure Equivalent (DVPE)."

105. Leach, F.C.P. et al., "The Effect of Fuel Composition on Particulate Emissions from a Highly Boosted GDI 
Engine-An Evaluation of Three Particulate Indices," Fuel 252 (2019): 598-611, https://doi.org/10.1016/j.

fuel.2019.04.115.

106. Leach, F., Knorsch, T., Laidig, C., and Wiese, W., "A Review of the Requirements for Injection Systems and the Effects of Fuel Quality on Particulate Emissions from GDI Engines," SAE Technical Paper 2018-01-1710, 2018, https://doi. org/10.4271/2018-01-1710.

107. Chapman, E., Winston-Galant, M., Geng, P., Latigo, R. et al., "Alternative Fuel Property Correlations to the Honda Particulate Matter Index (PMI)," SAE Technical Paper 2016-01-2250, 2016, https://doi.org/10.4271/2016-01-2250.

108. Wu, T. et al., "A Reduced PM Index for Evaluating the Effect of Fuel Properties on the Particulate Matter Emissions from Gasoline Vehicles," Fuel 253 (2019): 691-702, https://doi. org/10.1016/j.fuel.2019.05.059.

109. Ben Amara, A., Tahtouh, T., Ubrich, E., Starck, L. et al., "Critical Analysis of PM Index and Other Fuel Indices: Impact of Gasoline Fuel Volatility and Chemical Composition," SAE Technical Paper 2018-01-1741, 2018, https://doi.org/10.4271/2018-01-1741.

110. Moriya, H., "Fuel Property Influence on Exhaust Emissions Simplified PM Index," in SAE-China Congress \& Exhibition, Shanghai, 2016.

111. Wu, T.Y. et al., "Predicting Formula of Particulate Matter Emission from Gasoline Engines Based on Fuel Properties," Acta Scientiae Circumstantiae 40, no. 1 (2020): 102-110, https://doi.org/10.13671/j.hjkxxb.2019.0304.

112. Velji, A., Yeom, K., Wagner, U., Spicher, U. et al., "Investigations of the Formation and Oxidation of Soot Inside a Direct Injection Spark Ignition Engine Using Advanced Laser-Techniques," SAE Technical Paper 2010-010352, 2010, https://doi.org/10.4271/2010-01-0352.

113. Fatouraie, M., Wooldridge, M., and Wooldridge, S., "InCylinder Particulate Matter and Spray Imaging of Ethanol/ Gasoline Blends in a Direct Injection Spark Ignition Engine," SAE Int. J. Fuels Lubr. 6, no. 1 (2013): 1-10, https://doi. org/10.4271/2013-01-0259.

114. Fatouraie, M. et al., "Effects of Ethanol on In-Cylinder and Exhaust Gas Particulate Emissions of a Gasoline Direct Injection Spark Ignition Engine," Energy \& Fuels 29, no. 5 (2015): 3399-3412, https://doi.org/10.1021/ef502758y.

115. Yue, Z. and Som, S., "Fuel Property Effects on Spray Atomization Process in Gasoline Direct Injection," SAE Technical Paper 2020-01-0329, 2020, https://doi. org/10.4271/2020-01-0329.

116. Ding, C.-P. et al., "Effect of Engine Conditions and Injection Timing on Piston-Top Fuel Films for Stratified DirectInjection Spark-Ignition Operation Using E30," International Journal of Engine Research 21, no. 2 (2020): 302-318, https:// doi.org/10.1177/1468087419869785.

117. Park, S.H. et al., "Atomization and Spray Characteristics of Bioethanol and Bioethanol Blended Gasoline Fuel Injected through a Direct Injection Gasoline Injector," International
Journal of Heat and Fluid Flow 30, no. 6 (2009): 1183-1192, https://doi.org/10.1016/j.ijheatfluidflow.2009.07.002.

118. Zeng, W. et al., "Atomization and Vaporization for FlashBoiling Multi-Hole Sprays with Alcohol Fuels," Fuel 95 (2012): 287-297, https://doi.org/10.1016/j.fuel.2011.08.048.

119. Huang, Y. et al., "Spray and Evaporation Characteristics of Ethanol and Gasoline Direct Injection in Non-Evaporating, Transition and Flash-Boiling Conditions," Energy Conversion and Management 108 (2016): 68-77, https://doi. org/10.1016/j.enconman.2015.10.081.

120. Fioroni, G., Christensen, E., Fouts, L., and McCormick, R., "Heat of Vaporization and Species Evolution during Gasoline Evaporation Measured by DSC/TGA/MS for Blends of C1 to C4 Alcohols in Commercial Gasoline Blendstocks," SAE Technical Paper 2019-01-0014, 2019, https://doi. org/10.4271/2019-01-0014

121. Burke, S., Ratcliff, M., McCormick, R., Rhoads, R. et al., "Distillation-based Droplet Modeling of Non-Ideal Oxygenated Gasoline Blends: Investigating the Role of Droplet Evaporation on PM Emissions," SAE Int. J. Fuels Lubr. 10, no. 1 (2017): 69-81, https://doi.org/10.4271/2017-01-0581.

122. Rubino, L., Thier, D., Schumann, T., Guettler, S. et al., "Fundamental Study of GPF Performance on Soot and Ash Accumulation over Artemis Urban and Motorway Cycles Comparison of Engine Bench Results with GPF Durability Study on Road," SAE Technical Paper 2017-24-0127, 2017, https://doi.org/10.4271/2017-24-0127.

123. Roth, P. et al., "Catalyzed Gasoline Particulate Filters Reduce Secondary Organic Aerosol Production from Gasoline Direct Injection Vehicles," Environmental Science \& Technology 53, no. 6 (2019): 3037-3047, https://doi. org/10.1021/acs.est.8b06418.

124. Yoshioka, F., Kato, K., Aoki, T., Makino, M. et al., "Performance of Next Generation Gasoline Particulate Filter Materials under RDE Conditions," SAE Technical Paper 2019-01-0980, 2019, https://doi.org/10.4271/2019-01-0980.

125. Boehman, A.L., Song, J., and Alam, M., "Impact of Biodiesel Blending on Diesel Soot and the Regeneration of Particulate Filters," Energy \& Fuels 19, no. 5 (2005): 1857-1864, https:// doi.org/10.1021/ef0500585.

126. Williams, A., McCormick, R., Hayes, R., Ireland, J. et al., "Effect of Biodiesel Blends on Diesel Particulate Filter Performance," SAE Technical Paper 2006-01-3280, 2006, https://doi.org/10.4271/2006-01-3280.

127. Crawford, R. and Lyons, J., "An Improved Index for Particulate Matter Emissions (PME)," CRC Report No. RW107-2, 2021, https://3mpm51mqb7ryj2j12n04r01b-wpengine. netdna-ssl.com/wp-content/uploads/2021/03/CRC RW1072 2021.03.26.pdf.

128. Barrientos, E.J. et al., "Particulate Matter Indices Using Fuel Smoke Point for Vehicle Emissions with Gasoline, Ethanol Blends, and Butanol Blends," Combustion and Flame 167 (2016): 308-319, https://doi.org/10.1016/j. combustflame.2016.01.034. 


\section{Appendix}

TABLE A.1 Global PM standards for gasoline vehicles (all values converted to mg/km).

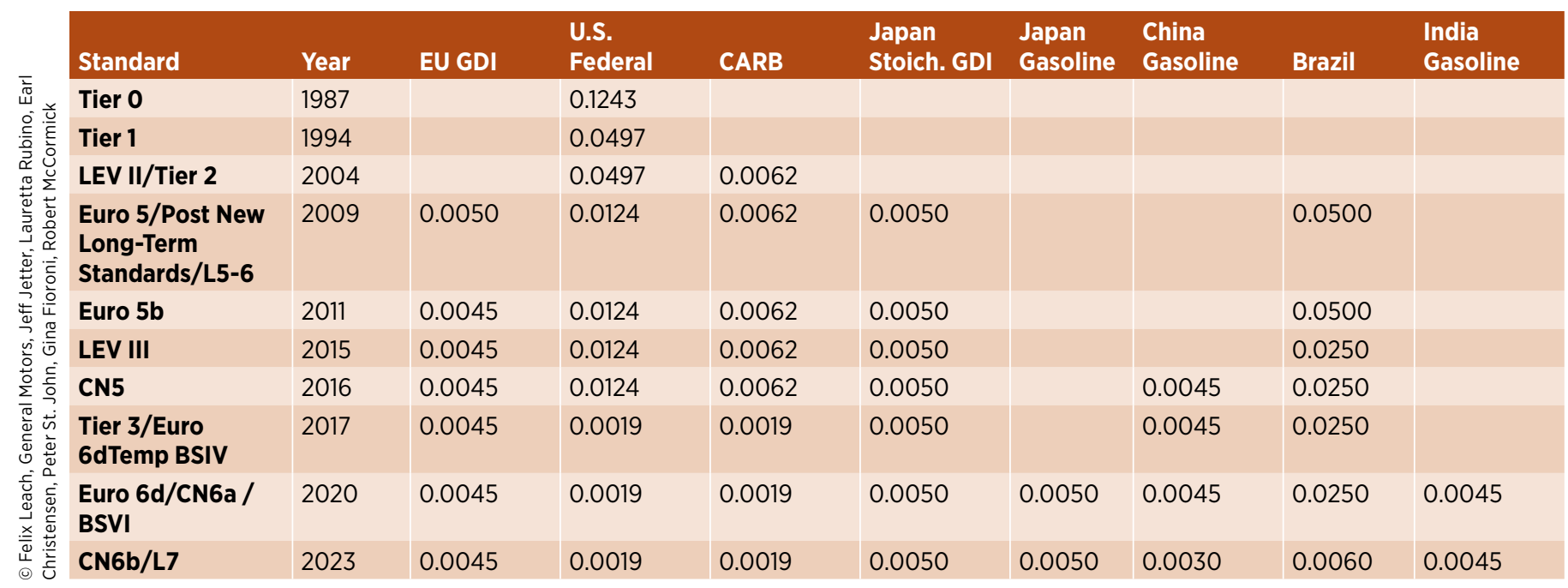

TABLE A.2 Global PN standards for gasoline vehicles (all values converted to \#/km).

\begin{tabular}{|c|c|c|c|c|}
\hline Standard & Year & EU-GDI & China-Gasoline & India-Gasoline \\
\hline Euro 6b & 2014 & $6.00 \mathrm{E}+12$ & & \\
\hline Tier 3/Euro 6dTemp BSIV & 2017 & $6.00 \mathrm{E}+11$ & & \\
\hline Euro 6d/CN6a/BSVI & 2020 & $6.00 \mathrm{E}+11$ & $6.00 E+11$ & $6.00 E+12$ \\
\hline CN6b/L7 & 2023 & $6.00 E+11$ & $6.00 E+11$ & $6.00 E+11$ \\
\hline
\end{tabular}


TABLE A.3 List of PM emissions indices.

\begin{tabular}{|c|c|c|c|}
\hline & Abbreviation & Equation & Reference \\
\hline \multicolumn{4}{|l|}{ Indices needing DHA } \\
\hline PM Index (2010) & PMI & $\mathrm{PM}_{\text {component }}=\frac{D B E+1}{V P_{[43 \mathrm{~K}]}} \times W t$ & {$[\underline{65}]$} \\
\hline $\begin{array}{l}\text { Menger/Wittmann Index } \\
\text { (2017) }\end{array}$ & MW & $\sum_{i=1}^{14} R a \cdot G e$ & [90] \\
\hline $\begin{array}{l}\text { Particulate Evaluation Index } \\
\text { (2016) }\end{array}$ & PEI & $\begin{array}{l}100 \\
\text { where } \mathrm{C \#} \text { is the volume percent aromatics at the stated carbon number }\end{array}$ & [92] \\
\hline $\begin{array}{l}\text { Modified Particulate } \\
\text { Evaluation Index (2021) }\end{array}$ & $P E I_{M O D}$ & $\mathrm{PEI}_{\mathrm{MOD}}=\sum_{i=7}^{13} A r_{i} \times C i+\frac{1}{V P\left(E t O H \text { at } 60^{\circ} \mathrm{C}\right)} V \%(E t O H)$ & {$[\underline{93}]$} \\
\hline Wu et al. (2020) & SPNI & $\mathrm{sPNI}=0.012 \times \mathrm{T} 70+0.048 \times \mathrm{HAC}+0.015 \times \mathrm{FBP}-0.034 \times \mathrm{OC}-2.721$ & [111] \\
\hline \multicolumn{4}{|c|}{ Simpler indices (not needing DHA) } \\
\hline Lemaire et al. (2019) & PMIC & $P M I C=\exp \left(\left[\left.F E S\right|^{2.34} \times\right.\right.$ LHV $^{-3.74} \times$ HOV $\left.\left.^{1.19}-C_{\text {base-fuel }}\right] \times 100\right)$ & {$[\underline{99}]$} \\
\hline PN Index (2012) & $\mathrm{PNI}$ & $\frac{\sum_{i=1}^{n}\left[D B E_{i}+1\right] V_{i}}{D \operatorname{VPE}(\mathrm{kPa})}$ & [101] \\
\hline Moriya (2016) & & sPMI v1 $=9.9241-0.0324 \times E 130-0.0647 \times E 170$ & [110] \\
\hline Moriya E150 (2016) & & sPMI v2 = $7.8511-0.0757 \times \mathrm{E} 150$ & [110] \\
\hline Threshold Sooting Index & TSI & $\mathrm{TSI}=a\left(\frac{M W}{h}\right)+b$ & {$[\underline{54}]$} \\
\hline Smoke Point & SP & ASTM Method D1322-18 & [59] \\
\hline Yield Sooting Index & YSI & $\begin{array}{l}Y S I_{i}=\left(Y S I_{A}-Y S I_{B}\right) \times \frac{f_{V, \max , i}-f_{V, \max , B}}{f_{v, \max , A}-f_{V, \max , B}}+Y S I_{B} \\
\text { where } f_{v, \max } \text { is the maximum soot volume fraction }\end{array}$ & {$[\underline{60}]$} \\
\hline
\end{tabular}

(c) 2022 Felix Leach, General Motors, Jeff Jetter, Lauretta Rubino, Earl Christensen, Peter St. John, Gina Fioroni, Robert McCormick. Published by SAE International.
This Open Access article is published under the terms of the Creative Commons Attribution License (http://creativecommons.org/licenses/by/4.0/), which permits This Open Access article is published under the terms of the Creative Commons Attribution License (http://creative

Positions and opinions advanced in this work are those of the author(s) and not necessarily those of SAE International. Responsibility for the content of the work lies solely with the author(s). 